MATERTAI, CONTROI IN NUCLEAR FUEL FABRICATION FACILITIES ;

PART II: ACCOUNTABILITY, INSTRIMENTATION AND MEASUREMENT TECHINIQUES IN FUEI FABRICATION FACILITIES P. 1236909

SAI Report No. SAI-79-825-WA

Giancarlo M. Borgonovi

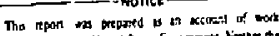

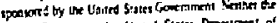

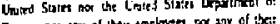

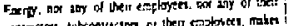

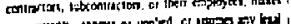

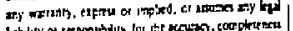

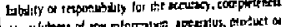

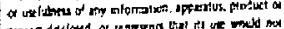
pineso discined, at reprerno of

Timothy J. McCartin

Thomas McDaniel

Charles L. Miller

Tien Nguyen

Interim Report for

Universicy of California Purchase Order 1236909

Prepared for:

Lawrence Livermore Laboratory

University of Califormia

Livermore, Califomia 94550

Submitted by:

Science Applications, Inc.

8400 Westpark Drive

McLean, Virginia 22102

(703) $821-4300$ 
TABLE OF CONTENTS

Secrion

$\underline{\text { Page }}$

1

INTRODUCTION AND SUMMARY.

2 MEASUREMENT TECHNIQUES.............. 3

2.1 Sensors and Measurement Devices.... 5

2.1.1 Buik Measurements......... 7

2.1 .2 I tem Measurements.......... 8

2.1.3 Automated Chemical Analysis. 11

2.1.4 Nondestructive Assay Systems 14

2.1.4.1 Receipts........ 14

2.1.4.2 Internal Transfers. 16

2.1.4.3 Shipments......... 17

2.1.4.4 Scrap and Waste.... 18

2.1.4.5 Holdup Measurements 20

2.2 Central Real-Time Material Control and Accountability Computer....... 20

2.3 Sumary...................... 21

References for Section $2 \ldots \ldots \ldots .23$

3 DESCRIPTION OF MATERIAI CONTROL AND ACCOUNIING SYSTEMS ................... 27

3.1 Closure of Material Balance...... 27

3.2 Overall Limit of Error in Inventory Difference (IEID) ............... 28

3.3 Advanced Techniques................. 33

3.4 NKC Regulations and Guides-Criteria for Nuclear Materials Accounting... 39

3.5 LEID and Diversion of Nuclear Katerial..................... 45

References for Section 3........ 49

4 ACCOUNTABILITY APPLICATION TO A MODEL FACILITY......................., 51

4.1 LEID Calculation................ 51

References for Section $4 \ldots \ldots \ldots \ldots$. 2 


\section{LIST OF FIGÜRES}

Figure

Page

2.1 Block Diagram of a Keal-Time Material

Control System...................... 6

3.1 Systematic Presentation of Material

Balance Accounting Sub-System and

Relationships..................... 29

3.2 Example of Application of V-Mask to

CUSUM Data......................... 40

3.3 Example of Application of the Alarm-

Sequence Chart.................... 41

3.4 Accounting Period Accuracy Required tc

Detect Diversion of 2 Kilograms of

Plutonium........................

$4.1 \quad \mathrm{MO}_{2}$ Process Line (Average flow per 8-h

shift $\ldots \ldots \ldots \ldots \ldots \ldots \ldots \ldots \ldots \ldots$

4.2 MBA-ICA Structure for Second-Floor Level of Vodel 200 MT Mixed Oxide/Year FuelRod Fabrication Plant................ 53

4.3 MA-ICA Structure for First-Floor Level of Model 200 MT Mixed-Oxide/Year FuelRod Fabrication Plant................ 54

4.4 Flow per Shift and Typical Inventories for $M B A$ No. $I$ in Model MOX Fabrication

4.5 Total LEID and Contributions to LEID for MBS No. I of Model $\mathrm{MO}_{2}$ Fabrication Plant 


\section{LIST OF TABLES}

Table

Page

2.1 Potential Application of Instrumentation to a Model MOX Fuel Fabrication

Plant........................ 22

3.1 Advanced Analysis Techniques for Nuclear Material Accounting............... 35

3.2 Fundamental Nuclear Material Controls... 43

3. 3 Predicted LEID for LWR Euel Fabrication Plant $(2 \sigma) . \ldots \ldots \ldots \ldots \ldots \ldots \ldots \ldots \ldots . . \ldots$

4.1 Measurement Methods and Uncertainties

for MAB No, $1 \ldots \ldots \ldots \ldots \ldots \ldots \ldots \ldots \ldots . \ldots$

4.3 Measurement Uncertainties on Typical Amounts of Fissile Material Used to

Compute Material Balance Uncertainties.. 58

4.3 Example of Plutonium IEID Calculation

for Kodel MBA (Bi-weekly Accounting

Period) ...................... 59 
1. INTRODUCTION AND SUMMARY

This is the second interim report on material control for nuclear fuel fabrication facilities, prepared for Lawrence Livermore Laboratory. The first report (SAI-78788-WA) and an addendum described the various fuel elentent types in use, the processes used in their fabrication, and the facilities that house the fabrication processes.

This report describes the ineasurement techniques, the instrumentation, and the procedures used in accountability and control of nuclear materials, as they apply to fuel fabrication facilities.

Since the purpose of the study was to provide an information thasis to LLL, some of the material included has appeared elsewhere and it has been summarized. An extensive bibliography has been included and the reader is referred to the original sources for more detailed information.

Section 2 contains a general discussion of instrumentation and measurement technqiues which are presently used or which are being considered for fuel fabrication facilities. In reviewing current application and fucure developments of instrumentation, those aspects which are most significant from the point of view of satisfying regulatory constraincs have been emphasized. Sensors and measurement devices have been discussed, together with theis interfacing into e computerized system designed to permit real-time data collection and analysis. Estimates of accuracy and frecision of measurement techniques have been given, and, where applicable, estimates of associated costs have been presented.

Section 3 contains a general description of material control and accounting, with a view towards its application to fuel 
fabrication facilities. In this section, the general principles of nuclear material accounting have been reviewed first (closure of material balance). dfter a discussion of the most current techniques used to calculate the limit of error on inventory difference, a number of advanced statistical techniques are reviewed. The rest of the section deals with some regulatory aspects of data collection and analysis, for accountabilicy purposes, and with the overall effectiveness of accountability in detecting diversion attempts in fuel fabrication facilities.

Section 4 contains a specific example of application of the accountability methods to a model fuel fabrication facility. The model facility, which is based on the Westinghouse Anderson design, has been described in the addendum of the first report. The effect of random and systematic errors on the total material uncertainty has been discussed, together with the effect on uncertainty of the length of the accounting period. 


\subsection{MEASUREMENT TECHNIQUES}

In its task force report on material control and ac. counting in safeguards, NUREG-0450, the NRC says the following:

"A major new thrust for safeguards recoumended in this report is the monitoring of the status of material during intervals between physical inventories. This would be achieved through the development of a monitoring program to srack material through a process to detect irregularities winch may have safeguards significance. ... current regulations do not adire.ss the use of prosess monitoring techniques for safeguarding materials. Research efforts in this area have been initiated and show promise. Examples include studies on Dynamic Material Control (DMMC), Controllable Unit Accounting (CUA), Safeguards Use of Process and Quality Control Data, Time Series Analysis, and Automation of Process and In-line Measurements. Before applying the results of such studies to safeguards, reference systems must be designed and tested for monitoring representarive processes. In addition, evaluation methods must be developed." (1)

The NFC concept is that real-time or rapid instrumentation and data analysis techniques will be applied at the MBA and sub MBA levels in order to detect larger diversions rapicty. These diversion detection sensitivities are expected to be capable of detecting the removal of as little as 5 effective $\mathrm{kg}$ of SMM during a two month inventory period.

The commission anticipates a continued (and perhaps upEraded in some cases) need for "cleanout" physical iriventories on a bimonthly basis. These inventories would have associated 
with them the high precision analytical measurements required to enable a facility to detect with high probability the diversion of five effective kilograms of SMM during an; 12 monch period.

This section deals largely with the first of these problems; the application and implementation of rapid and real time measurement techniques and accounting systems in fuel fabrication plants for the purpose of rapidly detecting diversion attempts. The sensitivity of such components and systems will be summarized along with their inherent precision and accuracy over the expected range of operation, the measurement control programs that may be required, the inherent resistance to tampering of the individual devices and the compusite system and an estimate of startup and operacing costs.

It must be realized that the best safeguard against diversion at the time of diversion is a physical security system that contains SiM and metal detectors at all exit portals from the material access area (MAA). These devices and other physical securicy sensors such as access control alarms etc. Will not be considered fur her here. The premise for this treatment is that such devices aay not exist in a facility or that they may be defeated by an insider acversary or that an additional detection device in the materials managemerit and accountability system (MiS) is desirable.

It must be further understood that any individual MuS measurement system cannot detect diversion Diversion can only be inferred by balancing beginning and material input with ending inventory and material shipments. This process, by nature, requires several determinations including measurements of input material, scrap and waste flows, product measurements 
and holdup materials. Since each of these measurements has an uricertainty associated with it, the combination of measurements has a resultant uncertainty. The object of any real time or rapid system is to produce these resultant balances in a rapid fashion with sufficiently small uncertainties so that the desired sensitivity to diversion is obtained while the false alarm rate remains acceptably low.

The basic configuration of a rapid material control system is shown in Figure 2.1. The function of the sensors and measurement devices is to interface with the materials and material flows and to provide information to the data base management system. The interactive terminals in the processing areas provide a two way flow of data between the process operators and the data base handling system. The computer manages the data base and organizes the data so that it can be readily evaluated. On command, or at specified intervals, it can examine all data obtained from all sensors and input terminals and evaluate the starus of all marerial within the facility. The results of this evaluation are output to the Nuclear Material Control person.lel. Each of these areas will be discussed in some detail below with emphasis on sersor and measurement devices.

\subsection{Sensors and Measurement Devices}

These are the actual measurement instruments and subsystems that feed data on the identities and quantities of nuclear material flowing or contained in plant systems.

They may be broken down in:o four major categories for discussion; 1) bulk measurements, 2) item measurements 3) automated chemical systems and 4) nondestructive assay systems. In discussing each of these in turn emphasis will be-placed on current usage in industry and the stare-of-the-art with respect to analytical capabilities and ease of interface into computer systems. 


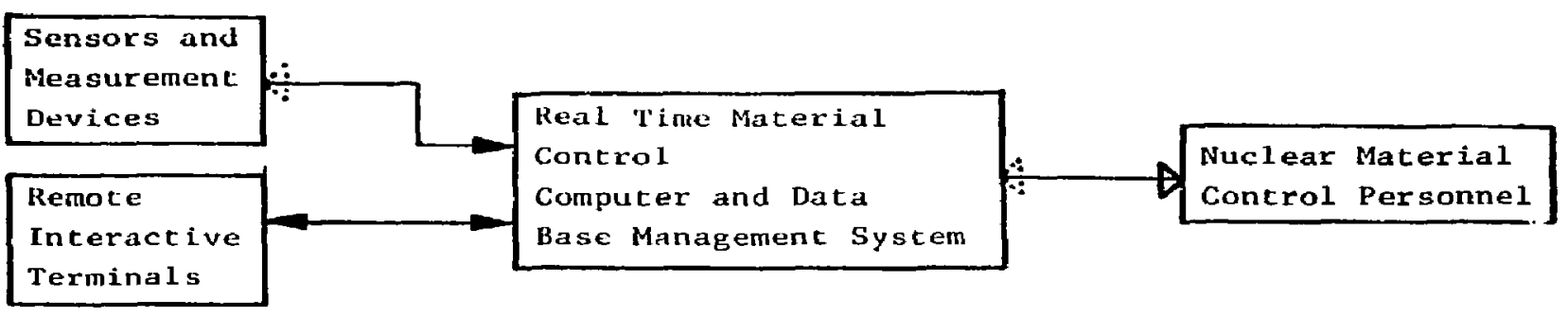

Figure 2.1 Block Diagram of a Real-Time Material Control System 
It should be emphasized that the estimates of precision and accuracy were in most cases taken from published data and may or may not accurately reflect the capabilities of a given instrument or technique for a specific purpose. In addition, actual cost data was used when available. In cases where this data was not obtained the authors judgement was used in presenting cost estimates.

\section{1 .1 Bulk Measurements}

For this report bulk measurements are considered to consist of weight and volume determinations. Weight determinations that are used for rapid accountability in a fiel fabrication plant are made on scales that consist of a weighing platform that contains the load cells and any hydraulic systems required. These weighing platforns will be designed for accountability use in a glove box atmosphere that contains ionizing radiation. The electronics muduics and interface to the computer system will normally be installed outside the actual material handling enclosures so that maintenance can be handled more easily. Commercially available scales using load cells are capable of weighing with a systematic error of 1 part in 20,000 or $0.01 \%$. (2) Since the electronics are digital, with proper platform design random weighing errors should be small. A discussion of these errors and methods of handling them statistically is presented by Jaech. (3) Systems of this type are currently operating in fuel fabrication plants with reasonable reliability. Inscalled costs are on the order of $\$ 10,000$ per unit. Annual operating costs are generally minimal.

Volume determinations for accountability purposes zenerally involve the use of accountability tanks. Flow measuremencs are generally not acceptable because of the 
requirement to integrate instantaneous rates over a period of time. For the fuel fabricat'on plancs in question there are very few situations where liquid volume determinations would be used.

Typical high precision tank level indicators use differential pressure methodologies for their meas'rements. These devices usualiy feed air or inert gases through tubes that extend to different levels within the tanks and measure the difference in lesisting pressure among the tubes. Tests conducted by the National Bureau of Standards show that these methods can detec liquid levels to within $0.02 \mathrm{~cm}(1 \mathrm{l})$. Information concerning tark geometries and tank inhomogenities are critica!. in detemining volumetric uncertainties of these systems. These factors contribute to the systematic errors associated with the tank calibrations. Temperature ef can be significant in precise volume determinations. For the sensitivities stated above changes in tank size anc bubble: tube iength as a functior. of temperature become imporcant variabies that can affect the random errors associated with volume determination. The use of electromanomerers and digitized thermocouple or thermisro: data should allow for precise volume determinations to be fed directly into the accoutability computer system in a real time framewcrk.

A system of this nature would probably cost from $\$ 5,000-$ $\$ 10,000$ per tank instrumented. The cost per tank should decrease as more canks are included in the system because the same microcomputer-based systen could handile data analysis for all tanks.

\subsubsection{Item Measurenents}

Ttem measurements for nuclear material control and aicountabilicy include two different types of instrumentation. The first of these is a device to determine that items tha: have been placed in storage in iten control area: have not 
been campered with or removed. The second device is an automatic container identification system that can be used to follow the transit of containers of SNM within the facility.

Several concepts have been studied to maincain surveillence of items that are being stored in vaults. These include radiation monitors, thermocouples and strain gauges and radio transponders on each container. Another concept is the use of remote indicating fiber optics devices incorpotated into shelf locks in the vault. There are obvious methods of defeat for each of these safeguards which would allow the ramoval of material without the knowledge of the safeguards system.

Probably the best system for assuring the safeguarding of items in storage utilizes a carousel that is controlled by a safeguards computer. Only authorized personnei can control the compucer and gain access to containers. Only one container can be accessed at a time from the carousel. Additional advantages of this system include the extra Iadiation shielding afforded by heving a secure carousel with all but one concainer behind concrete and automatic computer knowledge of the container removed. One possible drawback of this system is that the storage locations tend to be clustered and criticality constraints may be important.

Systems that can be used for following item movement within a facility vary from a manually processed transfer form to the use of automatic bar code scanning or optical character recognizion (OCR) systems. Most operational facilities today use the manwal system, however, many are upgrading to more automatec forms of material control data accumulation and data handling. (6-15) As the systems become more automated, additional applications of the concept are being implemented. For example, in some cases (12) the system will be used to maincain criticality control and in others laboratory operations will be scheduled b: the system. 
Most current bar code systems are inexpensive enough to be considered for in plant usage. They are rugged and reliable. They do, however, require specially printed labels affixed to containers. Advantages of this system over a manual system include reduced data input errors, red1-time data input and checking, ease and speed of operation and semi-automated physical invencory procedures.

Optical character recognition systens are more expensive than bar code systems and have a higher data rejection rate (or more stringent requirements on light pen motion during a reading operation). Most current generation bar code systems have the capability of printing alphanumeric information along with the coded information. This allows human reading of bar coded data which was cne of the prior drawbacks of such a system and one of the major advantages of the $O C R$ system.

Problems with either of these systems arise in identifying itsms such as sintering boats that routinely encounter an environment that is not conducive to plastic or paper label integricy. Alternative systems with permanent labels may be required for these applications.

System costs for automated storage facilities have not been developed, however, an estimate of $\$ 50,000-\$ 100,000$ for a single computer and two carousel units seems reasonable. Costs for bar coded item handling systerns are a function of the number of readers and the cumplexity of the system. Bar code reading terminals cost anywhere from $\$ 500-\$ 2500$ depending on options. The computer support system will cost $\$ 20,000$ or more depending on the configuration. Princers capaole of producing bar code labels are priced near $\$ 10,000$. Maincenance contracts usually run $\approx 1 \%$ of the purchase price per month. 


\subsubsection{Automated Chemical Analysis}

The New Brunswick Laboratory (NBL) of the Department of Energy (DOE) has developed a titrimetric method of analysis based on the Davies \& Gray method of uranium determination. $(16,17)$ This laboratory has systematically evaluated all interfering elemental species and developed chemical sample preparation procedures to eliminate these interferences. (18) Their procedure involves the tributyl phosphate in carbor tetrachloride extraction of aqueous nitrate medial followed by titration of the organic phase. The only interfering species that are not removed by this method are gold and technetium. Variations of this laboratory technique have the capability of reaching a precision of $\pm 0.005 \%$ relative standard deviation. (19)

The Lawrence Livermore Laboratory of the University of California has undertaken a project to automate this method. Their chosen technique uses a coulombic sitration with the electrogeneration of vanadium (V) titranc by constant current oxidation of $V(I V)$ which had bein previously reported. (21) The Livermore system incorporates commercially available automatic titrators, a sample changer, a programable current source, the electrode potential measurement subsystem, material handling subsystems and an electronic balance subsystem all interfaced to a laboratory minicomputer system.

The sample changer associated with the unit can handle and uniquely identify 400-300-ml beakers of previously prepared samples. Laboratory tests show a precision of 0.03 $\mathrm{mg} \mathrm{U}$ (A.S.D) on samples of $12-180 \mathrm{mg} U$ (21) $^{(21)}$ The accuracy of the determination ranges from -.15 to $+.20 \mathrm{mg} U$ and is a function of the quanticy of uranium titrated.

The current status of the instrumentation is that it is a first-of-a-kind instrument that is intended to automate 
laboratory analyses. The device requires the analyst to dissolve the sample and manually remove any interfering species. Input to the system includes weights of samples and aliquots and identification. The system will automatically add all necessary reagents and perform the titration. Once the end point is determined, the system calculates uranium values and prints complete information on the specific titration. The unit has a built-in fault detection system that detects abnormalities in the various subsystems.

A simple modification of this apparatus could be used for plutonium determinations. Los Alamos Scientific Laboratory is investigating the possibility of using a similar system for controlled potential or controlled-current modes of plutonium titration. (22). This electroanalytical method has precisions and accuracies similar to those quoted for the Livermore developed system. LASL is also evaluating an automated system for the rapid determination of plutonium and uranium either separately or in mixtures using an extraction-spectrophotometric method. (22)

In contrast to systems of this nature, any ac-line chemical analysis systems currently in use in fuel cycle plants are probably no more sophisticated than a simple visual end point ticration that is good to $\pm 10-15 \%$. These determinations are probably not used for sazeguards purposes but rather are necessary to determine SNM concentrations prior to a chemical creatment step that requires that concentrations be within a given range.

In order to use at-line chemical instrumentation for rapid accountability determinations the gap between the two extremes discussed above must be bridged. Problems and pitfalls in this process include adapting the multisample laboratory system to a manufacturing plant environment. 
Several economies may develop in this process due to the fact that all of the process materials at a given processing point will have similar chemical composition and one simple treatment procedure may be adequate for most or all samples. For example, gold and technetium are not likely contaminants in a MOX processing facility and, furthermore for most main stream materials there in no need for IBP extraction. A simple dissolution followed by automatic titration would suffice. The system will not need the flexibility that the laboratory system currently possesses and could be made with a microcomputer control and analysis subsystem rather than a minicomputer. In addition, the expensive sample idencification and optical reading systems would not be necessary for a single purpose at line instrument.

It is not unreasonable to assume that an operacor would be called on to collect a sample from the process, place the material in a pre-tare-weighed concainer and allow the automated system to conduct the analysis from that point on. If the sampling error were known or if a replicate sampling program were in operation the system output could be an analytical value with the associated uncertainty already computed.

In the process of ruggedizing the system some sacrifices could possibly be made in the analytical precision of the instrument. The worst case precision for low SMM materials is quoted a being $0.3 \%$, this is probably more than acequate to meet the material control requirements discussed by the NUREG-0450 document.

Capital costs of a multi-unic, off the shelf device would probably fall in the $\$ 30,000-\$ 50,000$ zange. Operating costs would average perhaps $\$ 5,000$ per year. 


\subsubsection{Nondestructive Assay Systems}

Probably the heart of any rapid or real-time material control system is the nondestructive assay instrumentation. This discussion will be limited to nondestructive devices that are applicable to materials flowing within a mixed oxide fuel fabrication facility. Even in that context the discussion will not be exhaustive or all inclusive. Several general references on nondestructive assay exist and the reader is referred to these for further background information. (23-26) Specific designs of nondestructive assay instrumentation for a reference $200 \mathrm{MT} /$ year MOX facility have been included in reports by Science Applications and LASL. ${ }^{(27-29)}$

This section of this report will generalize and sumarize the status of NDA in real-time material control and accountability for a MOX fuel fabrication plant.

\subsubsection{Receipts}

Incoming material will always be assayed by chemical means for elemental composition and isotopic determinations will be made by mass spectrometry. Weight verifications of both gross and tare weights will be carried out to complerely verify the shipper's data and inventory values. It is possible that a sampling plan for chemiral and isotopic determinations will be used while $100 \%$ weight verification continues. If this is done nuclear material content must be verified for each container received by a nondestructive techniqque.

For plutonium bearing materials calorimetry may be a potential method for checking SM content. This is discussed complecely in reference 30 . Problems associated with the technique involve a need for isotopic plutonium composition data and low throughput rates. No commersial instruments 
are available at this time, however, progress is being made on using pre-equilibration techniques and equilibrium prediction from heat flow measurements. With ideal packaging, pre-equilibration and a servocontrolled calorimeter ap-proximately $3 / 4$ hour are required for analysis of $1 \mathrm{Kg} \mathrm{JuO}_{2}$. Precision of calorimetric assay has been shown to be $0.03 \%$ to $0.37 \%(95 \%$ C.L. $)$ ( $^{(30)}$ Systematic errors were $0.023 \%$ to $0.14 \%$ in the same series of experiments. ${ }^{(30)}$

off-the-shelf microcalorimeters cost from $\$ 20,000-$ $\$ 40,000$. When developed, commercial large sample calorimeters should be in the range of $\$ 30,000-\$ 50,0,0$. Calorimeters are sensitive analytical instruments. They would be sensitive to various types of tanpering. The general conclusion from these remarks must be that calorimetry is currenty not a good candidate for high throsghput plutonium determination requirements. Developments in this field should be followed however and if speed of analysis can be improved and costs reduced it could be an effective production measurement tool.

Neutron counting, eicher gross or, coincidence counting can be used for measuring plutonium content of receipts. Analysis by this method is faster than calorimetry but not as accurate. Precisions of neutron coincidence determinacions are near $2-3 \%$ while systematic errors may be near $1 \%$ (31) Counting time is on the order of $5-15$ minutes per sample. These devices are somewhat less sensitive to rampering chan calorimeters and a standard can be counted frequencly to escertain that the instrument is operating properly. Costs of seutron well coincidence counters are a function of the size of the counting well and range from $\$ 10,000-\$ 20,000$.

In order for either the calorimetric or neutron counr:ing approaches to be applicable the plutonium and uranium iscropic compositions must be known. This infornation can come from the mass spectrometric determinations on laboratory samples 
or by passive gamma ray assay of individual containers. Passive gamma spectroscopy will yield a precision of $0.03-$ $3 \%$ depending on the counting time, the isotopic abundances and the particular gamma ray yield for individual nuclides. (31). The accuracy of the technique compared to mass spertrometric values can range from $0.03-7 \%$ depending on the same variables and the uncertainties in the half-lives and absolute gamma ray branching ratios or yields for the individual nuclides. Two methods of sample presentation are used routinely for gama spectroscopy. These are sample rotation and segmented scans. These tend to average out any inhomogeneities in the sample itself. Alternatively a far field scan of the entire container may be used. The distance from sample to detector should be large enough to minimize end effects and different distances from the edge and center of the container to the detector. Rotation may or may not be used. Gamma spectrometers with $\mathrm{Ge}(\mathrm{L} i)$ detectors can range from $\$ 10,000$ to $\$ 100,000$ depending on the options and capabilities. For fuels plant use a $\$ 10,000-$ $\$ 20,000$ unit should be adequate. These units are sensitive to tampering, however, frequent, rapid calibration checks can be made to detect any such tampering. Sample analysis times for precisions in the range discussed above are on the order of 15 minutes.

\subsubsection{Intermal Transfers}

Materials moving between MBAs and/or unit processes will generally be MoX powder or pellets (Scrap and waste from the various processes will be considered in a separate section). The rectniques described previously (calorimetry, neutron well coincidence counter, gamma spectroneter) are all applicable to measuring these movements. As discussed before, calorimetry is slow but more accurate and precise than the counting techniques. 
A modification of the $\mathrm{Ge}(\mathrm{L} i)$ spectrometer is suggested for measuring the transferted materials quantitatively. This involves using a gamma ray source on the opposity side of the container being counted from the $\mathrm{Ge}(\mathrm{Li})$ detector. By measuzing the attenuation in the gammas emitted from this source as it traverses the container being counted an attenuation correction factor may be developed. (25) This factor may be used to correct the observed sample count rate for gama ray self-attenuation in the sample itself.

Other instruments that may be used for measurement of intermediate product streams include a class of active devices that use neutron sources or in some cases other stimulating radiation, to induce fission events. The fission events are then detected using gamma and/or neutron counters in multiple coincidence to detect fission events. In some cases delayed neutrons are counted rather than the fission neutrons and gamas. Instruments that fall in this category are ISAS (Isotopic Source Assay System), Random Drivers, ISAF (Isotopic Source Adjustable Fissometer), $14 \mathrm{MeV}$ neutron generator induced fission, etc. These devices are discussed in detail in Reference (23) and (26). They will be discussed briefly in the section describing scrap and waste measurements.

\subsubsection{Shipments}

Product shipments from the $\mathrm{MO}_{2}$ fuel facility will consist of completed $\mathrm{MO}_{2}$ light water reactor fuel assemblies. Each fuel pin that goes into an assembly may be individually scanned using comercially available instrumentation. $(32-34)$ Most of these systems use an isotopic neutron source and prompt neutron gamma detectors in coincidence to measure fissile materials. Most of the systems can also be used in the passive mode without the neutron source if plutonium containing rods are being assayed. These devices are highly automated and can 
handle rods at a rate of $\sim 1 /$ minute. In one test known $\mathrm{UO}_{2}$ samples gave an accuracy of $0.7 \%$ relative standard deviation. The precision of the analysis was $0.5 \%$ at the $95 \%$ confidence 11mit. These values were determined, however, with a 1000 second analysis time. ${ }^{(32)}$ This type of accuracy and precision should not be expected on a high throughput scanner system. Westinghouse is currently using a Los Alamos designed pin scanner for shipper-receiver comparisons and input accountability measurements on all incoming FFTE drive: pins. System cost for the HEDI device was $\$ 95,000$ in 1972. Annual costs involve 1 technician as an operator. (37)

\subsubsection{Scrap and Waste}

Scrap and waste streams are the most difficult to measure accurately in a fuel fabrication plant. They are also the streams that historically have been measured by nondestructive assay, due, in part, to the difficulty with accurately sampling the material for more precise assay. Of the systems discussed previously, passive neutron counting and passive gamma-ray assay have been used extensively for scrap assay. $(25,31)$ Active systems such as the ISAS and ISAF have been used for scrap that is reasonably homogeneous. $(23,31)$ The active neutron interrogation systems are very sensitive to matrix materials. For example, if the matrix material contains a large amount of material with a high $(\alpha, n)$ cross section erroneously high SW deterwinations may result if this was not considered in some detail during instrument calibration. These problems are discussed in some detail in reference 26. Results of a particular study of ISAS analysis of scrap containers showed a mean relative difference from the known value of $-0.8 \%$ with a sigma of $6.8 \% .^{(31)}$ A comparison of the ISAS and random driver showed systematic errors of $2 \%$ and $7 \%$ and precisions of $11 \%$ and $21 \%$ (10) respectively. (31) Instrument costs are neaz $\$ 100,000$. One technician can operate and maintain these instruments. 
Another system that is valuable for scrap and waste assay is the Segmented Gama Scanner (SGS). This is a passive gamma assay device that automatically does the correction for transmission from an external gamma ray source and moves the sample relative to a collimated detector to give a segmented scan. Accuracies and precisions on such a device are no better than $10 \%$ to $50 \%$ for 55 gallon drums of low density containing homogenous materials. Prices of the commercially available instruments range from $\$ 50,000-\$ 80,000$ depending on options. One technician can keep the instrument operational and productive.

IRT Corporation has developed a waste assay system that uses an electron linear accelerator (LINAC) to produce a pulsed electron beam in the energy range 5-8 $\mathrm{MeV}$. This beam impinges on a tantalum converter to produce a bremsscrahlung spectrum up to $E_{\max }$ of the electron beam. This induces photofission and $(r, n)$ reactions in the sample. The prompt and/or delayed neutrons may be measured and the nuclear material content determined frow these measurements. ${ }^{(23)}$ Precision of these devices range from $1 \%-9 \%(1 \sigma)$ while the accuracy can vary between $2 \%-15 \%(10){ }^{(23)}$ These units are relatively expensive, and consequently, are not widely used in fuel fabrication facilities.

Very low level wastes (at or below the $10 \mathrm{nCi} / \mathrm{g}$ TRU level) of low density may be assayed by a Multi-Energy Gama Assay System (NEGAS) to determine if the material must be sent to retrievable storage or not. ${ }^{(38)}$ This computer controlled system uses a helical scan of cardboard containers containing low densicy wastes. A $12.7 \mathrm{~cm}$ diameter $\mathrm{NaI}$ detector is used to analyze three energy bands of interest (17 keV, $60 \mathrm{keV}$, $400 \mathrm{keV}$ ). The device is used as a "go-no go" decision poinc for non-retrievable waste disposal. The developers have determined sensitivities of $1.2 \mathrm{nCi} / \mathrm{g}$ at the $3 \mathrm{o}$ level of the 
instriment ${ }^{(38)}$. A prototype instrument has been used at the LASL plutonium facility for some years and a newer version is currently undergoing tests at the Babcock \& Wilcox FFTF fuel fabrication plant. Unit costs are $\$ 60,000-\$ 80,000$ and the unit can be operated by one technician.

\subsubsection{Foldup Measurements}

Two techniques have been proposed for measuring holdup in a plutonium fuel fabrication facility after cleanout. The first of these involves the use of a large area passive neutron detector. (39) The object of the instrument is to measure rapidly a large room volume with acknowledged low accuracy. The uncertainty associated with the measurements is believed

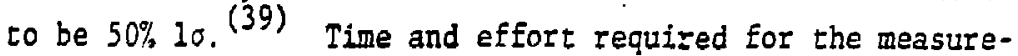
ments are low. This may be an acceptable technique in large throughput facilities where residual plant holduf is low and contributes little to plant LEIDs.

The second technique is wore time consuming and uses col. limated $2 " x 2^{\prime \prime} \mathrm{NaI}$ detectors and ${ }^{3}$ He neutron detectors. This method utilizes multiple counts of individual glove boxes and has shown agreement with recovered values to within $16 \%{ }^{(40)}$

\subsection{Central Real-Time Material Control and Accountability Computer}

Once all of the previously mentioned sensors have been installed and interfaced with the computer what should the computer software be able to do in order to detect diversion? The first and most obvious computation is a simple macerial balance for each MBA and ICA in the plant in real time. This computation would take into account the measurement uncertainties of each analytical system that furnishes data for the balance. Warnings and alarms would be generated if apparent diversions were discovered. 
Data from these balances would be accumulated over an extended pertod of time so that sophisticated statistical tools such as cusurs and Kalman filtering can be applied. These methods allow for the more sensitive detection of long term diversion of individually small quantities of SM.

These techniques will be discussed more fully in the following sections on Accountability.

\subsection{Sumary}

Table 2.1 presents a sumary of the applications of sensors and measurenent devices to difierent detection JI measurement problems in a MOX fuel fabrication facility. The references cited provide additional detai. on any of the techniques or specific systems mentioned.

In many cases instrumentarion has been developed ano tested in a laboratory environment only. Full-scale plant testing has not taken place. In other cases the state-of-theart is not sufficiently developed to provide input data of the quality necessary to meet the NRC criteria in a rapid or near real-time environment. Other situations exist where the instrumentation is available commercially and has been installed and utilized in a production atmosphere for some time. 


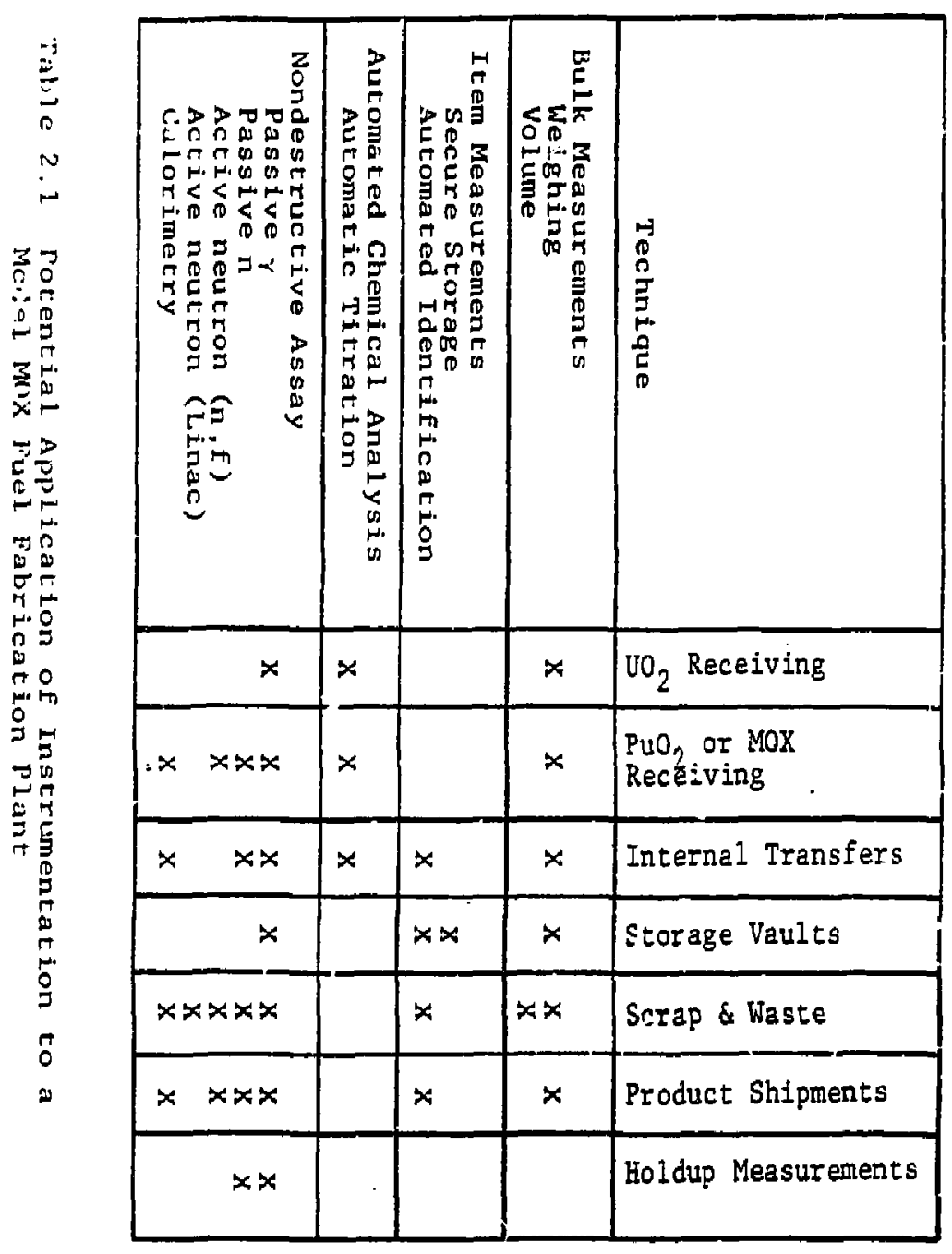


i. Office of Nuclear Material Safety and Safeguards, U.S. Nuclear Regulatory Commission, "The Role of Material Control and Accounting in the Safeguards Program," NUREG-6450, VoI. 1-4, Apri1, 1978 .

2. Pomernacki, C., et.al., "Technical Appendix for the Special Safeguards Study on Material Concrol and Accounting Systems", Lawrence Livermore Laboratory, September 15, 1975.

3. Jaech, J.L., "Rounding Errors in Weighing", Journal of the Institute of Nuclear Materials Management, Vol.V, No. II, Sumuer, 1976.

4. Rodden, C.J., "Selected Measurement Methods for Plutonium and Uranium in the Nuclear Fuel Cycle", 2nd Ed., USAEC Technical Information Center, Oak Ridge, Tenn. 1972:

5. Suda, S.C., "Instruments and Data Analysis Methods for Volume Measurements". Proceedings of a Symposium on Safeguarding Nuclear Materials, VoI. II, paper IAEA-Sh-201/25., October, 1975 .

6. Baston, M. and Bishop, T.C., "The Application of Real Time Data Processing to Mound Laboratory's SS Accountability System", Journal of the Institute cf Nuclear Materials Managenent, Vo1. IV, No. III, Fall,1975.

7. Sarich, J. 7., "Ral Time Plutonium Accountability and Inventory Control System", Journal of the Institute of Nuclear Matexials Management, Vol. IV, No. III, Fa11, 1975.

8. Akursh, H., et.al. "A Real-Time Accountancy and Control System at Plutonium Fuel Facility of PNC", Journal of the Institute of Nuclear Materials Management, Vol. IV, No. III, Fall, 1975.

9. Augustson, R.H., "Developement of In-Plant "Real-Time" Materials Control-the DMMAC Program", Journal of the Institute of Nuclear Materials Management, Vol. V, No. III, Fall, 1976.

10. Croom, R.G., "Savannah River Plant's Accountability Inventory Management Systems (AIMS)". Journal of the Institute of Nuclear Materials Management, Vol. V, No. III, Fall, 1976.

11. Roberts, N., et.al., "Minicompucer Based, Controlled Materials Information System", Journal of the Institute of Nuclear Matertals Management, Vol. V, No. III, Fall, 1976. 
12. Affel, R. G., et.al., "ORNL Nuclear Materials Criticality, Accountability, and Safeguards Control as Supported by an On-Line Computerized System", Journal of the Institure of Nuclear Materials Management, Vo1. V, No. III, Fall, 1976.

13. Kotte, U., et.al, "Development of an Integrated, Computerized Accountancy System for Nuclear Materials Control in a Nuclear Research Centre", Journal of the Institute of Nuclear Materials Mariagement, Vol. V, No. III, Fall, 1976.

14. Carlson, R.L., et.aI., "Advanced Accounting Techniques in Automated Fuel Fabrication Facilities", Journal of the Institute of Nuclear Materials Management, Vol.V, No. III, Fal1, 1976.

15. Baston, M., et.al., "Mound Laboratories Rea1-Time Accountability System", Journal of the Institute of Nuclear Materials Management, Tol. VI, No. III, Fa11, 1977.

16. Davies, W. and Gray, W., Talanta, II, 1203, 1964.

17. New Brunswick Laboratory Titrimetric Method for the Determination of Uranium-Basic Procedure," Appendix A, NBL-272, October, 1974.

18. Pietri, E. E., Scarborough, J.M., and Bingham, C.D., "Survey of Uranium Assay Techniques and Measurement Control at the New Brunswick Laboratory." Journal of the Institure of Nuclear Materials Management, Vol IV, No. III, Fall, 1975.

19. Eberle, A.R. and Lezner, M.W., NBL 272, Occober, 1974.

20. Harrar, J. E., et.al., "An Automated Sample-Processing and Titration System for the Determination of Uraniun", Journal of the Institute of Nuclear Materials Management, VoI. V, No. III, Fal1, 1976.

21. Goldbeck, C.G. and Lerner, M.W., Anal. Chem. 44, 594 (1972).

22. Jackson, D.D., Marsh, S.F., Rim, J.E. and Waterbury, G.R., "Recent Developments in the Dissolution and Automated Analysis of Plutonium and Uranium for Safeguards Measurements". Proceedings of a Symposium on Safeguarding Nuclear Materials, Vol. II, paper IAEA-SM-201/18, Oct., 1975.

23. Kul1, L.A.," Catalogue of Nuclear Material Safeguards Ingtruments", Brookhaven National Laboratory BNL 17165 , August, 1972. 
25. Reilly, T. D, and Parker, J, L., "A Guide to Gamma-Ray Assay for Nuclear Material Accountability", Los Alamos Scientific Laboratory, LA-5794-M, March, 1975.

26. Gozani, T.," Active Nondestructive Assay of Nuclear Materials, Priciples and Applications", Science Applications, Inc., SAI089-78-PA, May, 1978.

27. Bain, Jr., E.E., et.al.,"An Evaluation of Real-Time Material Control and Accountability in a Model Mixed Oxide Fuel Plant," Science Applications, Inc., SAI-75-648-LJ, Sept. 15, 1975.

28. Bray, G.R., et.al.,"Material Control and Accounting for Plutonium Recycle Facilities", Science Applications, Inc., SAI-76-539-LJ, March 4, 1976.

29. Shipley, J.P., er.al.,"Coordinated Safeguards for Materials Management in a Mexed-Oxide Fuel Facility", Los Alamos Scientific Laboratory, LA-6536, February, 1977.

30. Rodenburg, W.W., "An Evaluation of the Use of Calorimetry for Shipper-Receiver Measurements of Plutonium", Monsanto Research Corporation, NUREG/CR-0014, MLM-2518, June, 1978.

31. Reilly, T. D. and Evans, M.L., "Measurement Reliability for Nuclear Material Assay", Los Alamos Scientific Laboratory, LA-6574, January, 1977.

32. Olsen, R. N., "A New Automated Pellet/Powder Assay System". Journal of the Institute of Nuclear Materials Management, Vol IV, No. III, Fal1, 1975.

33. Kubik, R.N. and Pettns, W. G., "Experience with a Fuel Rod Enrichment Scanner", Journal of the Institute of Nuclear Materials Management, Vol. IV, No. III, Fall, 1975.

34. Miller, H. and Shepard, S.H., "Recent Developments of Multichannel High Speed Fuel Rod Assay System", Journal of the Institute of Nuclear Materials Management, Vol. IV, No. III, Fall, 1975 .

35. Goris, P. and De Merschman, A.W., "Fast Flux Test Facility (FFTF) Fuel-Pin Non-Destructive Assay Measurements", Proceedings of a Symposium on Safeguarding Nuclear Materiais, IAEA-SM-201/84, October, 1975.

36. Goris, P. "Rod Scanner Assay of FFTF Fuel", Hanford Engineering Development Laboratory, HEDL-TME 77-29, 1977.

37. Goris, P., private commurication, 1978. 
38. Crane, T. W., et.al., "Assay of Fission Product Contaminated Combustible Waste at the $10 \mathrm{n} \mathrm{Ci} / \mathrm{g}$ Fiducial", Journal of the Institute of Nuclear Materials Management, Vol. VI, No. III, Fall, 1977.

39. Tape, J. H., et.al. "Total Room Holdup of Plutonium Measured With a Large-Area Neutron Detector", Journal of the Institute of Nuclear Materials Management, VoI. V, No. III, Fall, 1976.

40. Kindle, C. H., "Institute Measurement of Residual Plutonium", Journal of the Institute of Nuclear Manterial Management, Vol. V, No. III, Fall, 1976. 
3. DESCRIPTION OF MATERIAL CONTROL AND ACCOUNTING SYSTEMS

In this chapter a brief description of material control and accounting, with a view towards ils application to fuel fabrication facilities, is presented. The material is of a background nature, and although some of what is presented appears in previous SAI reports, it has been included here in an edited version for information purposes. $(2,15,17)$

In what follows, the principles of slosed material balance are reviewed first, for the purpose of introducing the basic concepts. The analytic techniques ised to compute the limit of error, or uncertainty, on the material balance, are then discussed, together with a number of advanced statistical techniques. Rules and regulations which have an impact on conducting a nuclear accounting program at a fabrication facility are reviewed next. Finally, a discussion of the effectiveness of material control and accounting in detecting diversion attempts is given.

\subsection{Closure of Material Balance}

Material balance accounting is based on the following basic concepts :

- Classical Accuunting. This involves debiting and crediting measured quantities of nuelear waterial whenever the material physically enters or leaves areas designated as a material balance area (MBA) or item accounting area (ICA). In addition, the MRA must be periodically inventoried.

- Nuclear Material Heasurements. This involves a variety of techniques to determine the quantities to be used in the material balance equations. The relevant measurement techniques have been discussed in Section 2 .

- Measurement Control. Since the measurements are not exact, it is Important to pstablish a measurement control prograw, to ensure that the assnciated uncertainties are knowr. and to maintain a consistent performance of the measur emeñts. 
- Statistical Methods. Since the reasurement results are random variables, with an associated probability distribution, statistical methods are used to analyze the data. The most common statistical analysis involves the calculation of the inventory difference (ID, also known as MUF, for material unaccounted for) and the uncertainty, or limit of error, on inventory difference (LEID, also known as LEMUF, for limit of error on material unaccounted for).

- Inspections and Audits. This involves periodic checks perFormed by management and the NRC to ensure that the information used is reliable.

Figure 3.1, from Reference 17, shows the relationship of the various material balance accounting sub-systems. Measurements are performed, usually at key measurement points (KMP), on the nuclear material flowing between MBA's. The transfers are monitored and recorded by the accounting system, while the measurement control program guarantees a consistent performance of the measurements. This is done by statistical analysis of the measurements to provide error estimates. A model of the measurement process can be useful here, to establish the extent of the measurement control program necessary. Inventories of all the material present in the facility are taken periodically, and used, together with the measured transfers, to compute estimates of ID and LFID. The results are reported to management and NRC, who may also periodically audit the performance of the complete material accounting system.

\subsection{Overall Limit of Error in Inventory Difference (LEID)}

The Inventory Difference (ID) is computed from the following components:

$$
I D=B I+R=S-E I
$$

where $B I=$ beginning inventory

$E I=$ ending inventory

$R=$ receipts

$S$ = shipments 


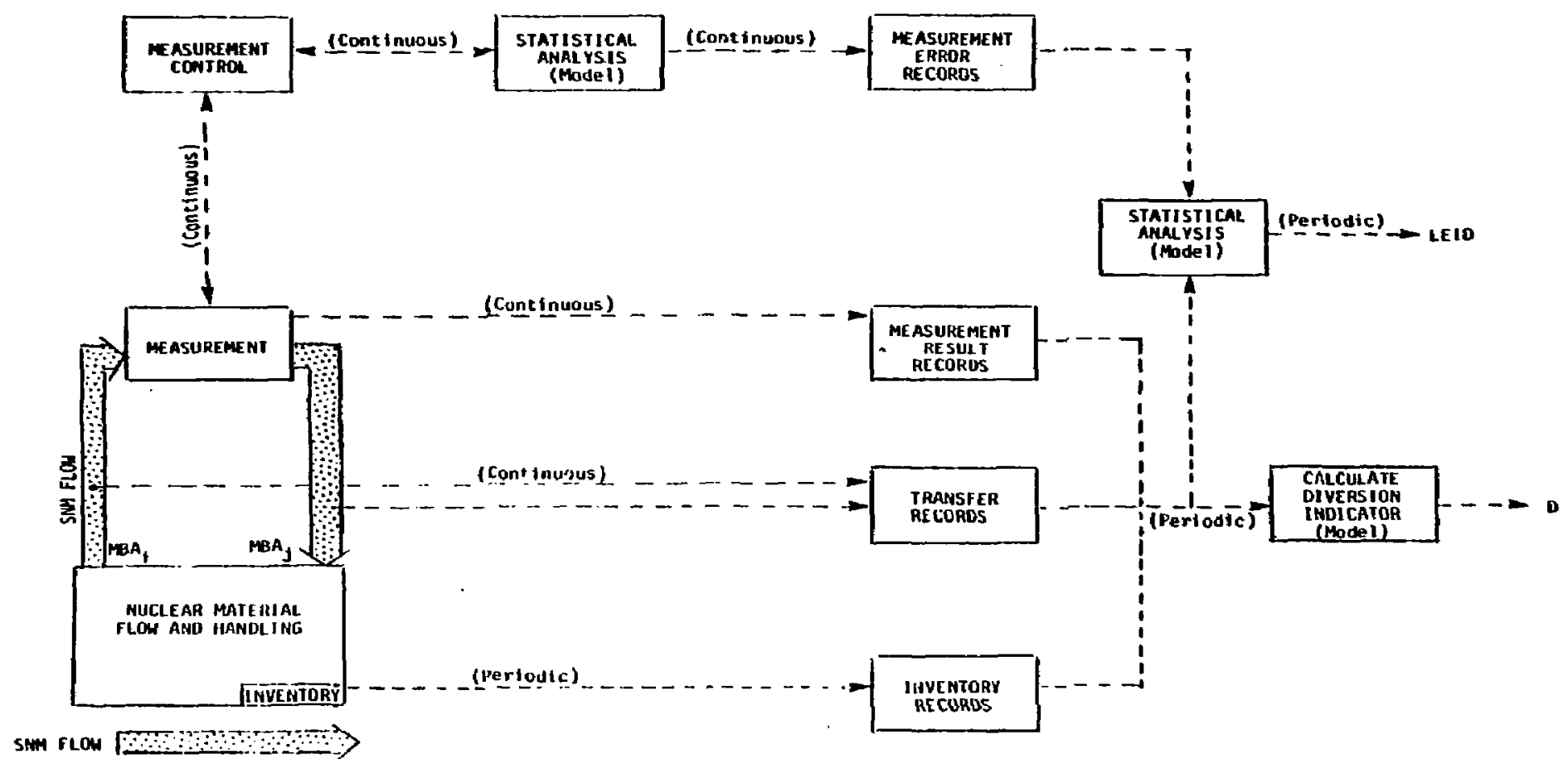

INFOPMUTION FLOH - - - $\ldots$

Figure 3.1 Schematic Presentation of Material. Balance Accounting Sub-Systemi and Relationships (from ref. 17). 
The ID is computed by substituting the individual component terms for each category of material in the equation, i.e., BI, EI, R, and $S$. Comon terms are cancelled, i.e., items appearing in more than one category with a different sign cancel in the above equation. Beginning and ending inventories must inciude material in storage, in process, and holdup in equipment, pipes, and filters. Similarly, inputs to and shipments from the MBA must include processed material, waste, and scrap. Because of the finite accuracy of the measurements, inventories and transfers are random variables. and the ID itself is a random variable with an associated probability distribution. Twice the standard deviation of this probability distribution has become known as LEID, or limit of error on inventory difference.

In the real operation of a facility, such as a fuel fabrication facility, ID values are periodically calculated and compared to the estimated LEID. In a conceptual study, the ID itself is non-essential (unless simulation techniques are used) and one is interested in the LEID only, Then words such as "typical ID" are encountered, they should be interpreted as limit of error, or uncertainty, on inventory difference.

Because of the obvious interest in having a LEID as small as possible, a general discussion of the factors which influence the LEID is appropriate. Broadly'speaking, the LEID is a function of a number of variables, which can be characterized into two groups, as follows:

- The first group contains variables which are determined by the technology available. These variables are the accuracy and precision limitations of the instruments and techniques used in the measurements.

- The second group contains variables which can in principle, subject to some practical constraints, be controlled by administrative decision. These variables are the frequency of inventory taking and the size of the material balance area, The frequency of inventory taking affects the transfers to the $M B A$, while the size of the $M B A$ affects both transfers and inventories. 
The LEID can be calculated according to the model described in detail in a PNL study. (3) The following equations were used:

$$
\text { LEID }=20
$$

$$
\begin{aligned}
& \sigma^{2}=\sum_{1} \sigma_{1}^{2}(f 10 w)+\sum_{j} \sigma_{j}^{2} \text { (1tew inventory) + } \\
& \sum_{k} N_{k} \sigma_{k}^{2} \text { (bulk inventory). } \\
& \sigma_{i}^{2}(\varepsilon 20 w)=\left(m_{1} n_{1} F_{i}\right)^{2}\left[\left(r_{1}^{2} / \pi_{i} n_{1}\right)+\left(p_{1}^{2} / \pi_{1}\right)+q_{i}^{2}\right\}
\end{aligned}
$$

$i=$ Inde.: for each flow stream (feed, product, clean scrap, dirty scrap, liquid waste, solid waste, analytical samples, etc.).

$F_{i}=$ average quantity of plutonium per batch or unit time period in the ith flow stream.

$n_{i}=$ average number of batches transferred or unit time periods elapsed for the ith flow stream per calibration period for the plutonium assay instrumentation.

$m_{i}=$ average number of calibration periods for the $i$ th flow stream per accounting period.

$\left(m_{i} n_{i} F_{i}\right)=$ average quantity of plutonium transterred in the $i$ th flow stream per accounting period

$I_{i}=$ one-sigma relative random measurement uncertainty.

$r_{i}^{2}=\frac{r_{w i}^{2}}{N_{w i}}+\frac{r_{s i}^{2}}{N_{s i}}+\frac{r_{a i}^{2}}{N_{a i}}$

$\Sigma_{w}=$ one-sigma relative random uncertainty associated with weight, volume or NDA measurement.

$N_{w}=$ average number of weight, volume of NDA measurements per batch or unit time period.

$r_{s}=$ one-sigma relative random uncertainty associated with sampling.

$N_{s}$ - average number of samples taken per batch or unit time period.

$F_{a}=$ one-sigma random uncertainty associated with laboratory analyses of plutonium concentration.

$\mathrm{N}_{a}$ - average number of times each sample is analyzed for its plutonium concentration. 
$P_{i}=$ one-sigma relative short-term systematic measurement uncertainty.

$p_{i}^{2}=p_{w i}^{2}+p_{s i}^{2}+p_{a i}^{2}$

$P_{w}=$ one-sigma relative short-tern uncertaincy associaced with weight, volume or NDA measurement.

$P_{S}=$ one-sigma relative short-term uncertainty as sociated with sampling.

$P_{a}=$ one-sigma relative short-term uncertainty associated with laboratory analysis of plutonium concentration.

$q_{i}=$ one-sigma relative long-term systematic measurement uncertainty

$q_{i}^{2}=q_{w i}^{2}+q_{s i}^{2}+q_{a i}^{2}$

$q_{w}, q_{s}$ and $q_{a}$ are defined in the same manner as $p_{w}, p_{s}$ and $p_{a}$

$\sigma_{j}^{2}$ (item inventory) $=\left(c_{b j}+C_{e j}\right) I_{j}^{2} r_{j}^{2}+\left(c_{b j}^{2}+c_{e j}^{2}\right) I_{j}^{2}\left(p_{j}^{2}+q_{j}^{2}\right)$

$j=$ index for the $j$ th type of item container.

$c_{b j}$ and $c_{e j}=$ average number of $j$ th type of item containers, each with an average plutonium content of $I_{j}$, which are counted: at the beginning and end of an accounting period, respectively.

$I_{j}, p_{j}$ and $q_{j}$ are defined in the same manner as $r_{i}, p_{i}$ and $q_{i}$.

$\sigma_{k}^{2}$ (bulk inventory) $=\left(I_{b k}^{2}+I_{e k}^{2}\right) r_{k}^{2}+(F D)\left(I_{b k}-I_{e k}\right)^{2}\left(p_{k}^{2}+q_{k}^{2}\right)$

+ (FS) $\left(I_{b k}^{2}+I_{e k}^{2}\right)\left(p_{k}^{2}+q_{k}^{2}\right)$.

$k$ - index for the $k$ th type of bulk storage container.

$I_{b k}$ and $I_{e k}=$ average plutonium content of the $k$ th type of bulk storage container at the beginning and end of an accounting period, respectively.

$r_{k}, p_{k}$ and $q_{k}$ are defined in the same manner as $r_{i}, p_{i}$ and $q_{i}$.

FD (Fraction of D1fference) and FS (Fraction of Sum) are fractions which add to unity. It is appropriate to use the difierence term (i.e., FD $=1,0$ and $F S=0$ ) when the plutonium content of a bulk storage container is determined in a manner which suggests that systematic uncertainties tend to cancel so that the nat uncertainty is determined by the difference between two measurements. Alternatively, it is appropriate to use the sum term (i.e., FD $=0$ and FS $=1.0$ ) when the nature of

Plutonium containers which zemain sealed throughout an accounting period are not counted for purposes of determining material balance uncertainty. 
the measurements indicates that the systematic uncertainties are additive.

$N_{k}=$ number of the $k$ th type of bulk storage containers.

\section{3 Advanced Techniques}

The concepts of inventory difference and limit of error on inventory difference have been introduced primarily to detect single latge thefts which occur during one accounting period. Regulations prescribe specific actions to be taken when the ID for an MBA in a nuclear facility, such as a fabrication facility, exceeds a threshold specified in LEID units. Since the ID is a random variable with an associated probability distribution, the threshold implies the existence of a detection probability, its complement to one or miss probability, and a false alarm probability.

Because of the increased concern for the diversion of special nuclear material, efforts have been made to extend the above concepts to the situation in which several small thefts, each smaller than the LEID, take place over a sequence of accounting periods. These efforts, which have generated a number of analysis techniques, have been based on the application of estimation thecry and decision theory.

Estimation theory permits one to obtain optimal (minimum variance) estimates of a state vector, given noisy measurements of some of the components of this vector. The optimal estimate is obtained by using information (such as causal relationships) which may be known about the state vector in addition to the measurements.

Decision theory permits one to select one of two hypotheses, based on a set of values of measured variables, and some statistical assumptions about the probability of obtaining suci values given that one or the other hypothesis is true.

This section sumarizes the advanced techniques which have been applied to the analysis of sequences of inyento $y$ differences. At this time, it has not been demonstrated triac one $c$ t the 
advanced teciniques is definitely superior to the others. instead, the consensus saems to be that a battery of statisicical tests should be employed, and used as a management tool, not as a substitute for management ${ }^{(4)}$.

The advanced techniques to be described operate on a sequence of inventory differences or on another statistical sequence which has been generated from a sequence of ID's. The techniques seem to fall into three categories, namely:

- Techniques meant to represent the acsountability data and/or their analysis in a form which facilitates the identification of trends. The Shewhart control chart and the alarm-sequence chart belong to this category.

- Techniques meant to generate better estimates of the dața, by some kind of statistical filtering. Examples are the CUSUM, the Kalman filter, and the linear combination of inventory differences.

- Techniques meant to provide a criterion for the cnoice of one hypothesis (diversion took place) over the other (no diversion). The $V$-mask and the Wilcoxon test belong to this category.

Table 3.1 surmarizes the main characteristics of the princifa! advanced techniques. Although other methods of analysis have been proposed $(5)$, the ones iisted in Table 3.1 have been used चore frequen:ly and have been epplied to the analysis ci real or simwlaced data from existing or conceptual fuel abrication facilities. The individual Lechniques are now described separacely.

\section{Shewhart Chart}

One of the siriplest time series analysis techniques is the Snetinart char: ${ }^{(6)}$, which is used widely in industry for process contrul. The chart cunsists of plotting measured data sequentially together with warning and action limits. The warning limit is usually ner at tha 2-2 level, while the action limit is se: at the 3-0 level. For nuclear material accounting, the 3hewhart chart is a sequential plot of the inventory differences, cftan with their 1-e ezcor bars. This chart is used because of its situricity, aitiough it is generally recognized that its power in identifying trends associated with long-term diversion is anmewhat limited. 


\section{Cumulative Sum}

The cumulative sum ${ }^{(7)}$, or CUSUM, is simply the unweighted sum of the raw data. In safeguards applications, the CUSUM is the sequential sum of inventory differences. The CUSUM statistic, which estinates the cumulative mean. loss, is a more sensitive indicator of loss than the inventory difference. The detection of long-term diverston is generally based on identifying the presence of trends in inventory difference data, and the custM statistic is the simplest tool for identifying such trends. This statistic can be considered as the result of the application of a filter to the raw data (inventory differences). Although this filter is not optimal, in the sense of minimum variance, the results obtained are not significantly inferior to the ones obtained with more sophisticated filtering procedures, if the uncertainties are mainly attributable to inventory measurements rather than transfer measurements.

\section{Kalman Filter}

The Kalman filter ${ }^{(8,9)}$ is perhaps the best known tool of estimatior theory. Because of its computational convenience, it his been appiied widely to conmunications and control systems, ithere large quantities of data must be processed and the signals are contamjinated by noise.

Real time ur dynamic nuclear material accountability generates daca wisich contain a stochastic component (measurenent uncertainties). Long-term diversion carried out over seve-al accounting periods would produce a small signal which is juried in the noisy measurements. The Kalman filtering technique, with its potential for providing estimates of the weak diversion signal, assumes therefore an important role as an advanced safeguards technique.

The Kalman filter can be considered as a generalization of the least squares method. In using the least squares method, one combines some experimental information with some theoretical information to obtain the best estimate (the one with minimum var- 
iance) of some parameters. The Kalman filter also combines experimental information and theoretical information to obtain the best estimate of the state of a system.

Generally speaking, the least square method is applied to systems which are described by functioned forms containing parameters. Conversely, the Kalman filter is applied to systems which are described by an operator, or differential equations, or difference equations. This gives the Ralman filter a dynamic connotation, which is further emphasized by its recursive properties. The use of this technique does not require the storage of an entire sequence of data. Rather, the new estimate is computed sequentially from the previous estimate and the new measurement.

Pike and Morrison ${ }^{(10)}$ have pioneered the application of the Kalman filtering technique to nuclear waterial accountability. The state of the system is described by the inventory at the end of an accounting period and by the loss (diversion) during the same period. A model for diversion is required for application of the Kalman filter equations, the simplest model being ore in which the average loss remains constant from one accounting period to the naxt. The aigorithm provides estimates of both inventory and loss, together with an estimate of their variance.

Repeated application of the Kalman filter technique to sequences of simulated data has shown that the technique is indeed more efficient than the CUSin in detecting small continuing losses. This is so, however, when the uncertainties on transfers are onich less than the uncertainties on inventories, a situation which is verified only for very short accounting periods.

\section{Linear Combination of Inve:atory Differences}

Jaech $^{(11)}$ has introduced a minimum variance analysis technique that consists of a linear combination of inventory differences. The CUSUM statistic is a particular case of this combination, with the coefficients being all equal to one. Under the assumption of constant loss per period, a better statistic (that is one with smaller variance) can be obtained by properly shoosing the coefficients of the linear combination. In fact, an 
optimal statistic can be chosen, by computing the variance of the statistic and calculating its partial derivatives with respect to the coefficients. By setting the derivatives equal to zero, one can find a set of coefficients which gives the optimal combination. Jaech has shown that this statistic is as discriminating as the Kalman filter in detecting a constant small loss extending over several accounting periods.

From the computational point of view, the algorithm is not as convenient as the Kalman filter algorithm, since it is not recursive, and it requires storing the complete history of past inventory differences. However, its application is more straightforward, since no initial estimates have to be assumed (one reeds initial estimates of the state and its covariance to start the Kalman Filtering orocess).

\section{Wilcoxon Test}

Optimal analysis of data is based on the assumption that the statistical distribution of signals and noise is known. If the distribution is not known or if it belongs to a class so wide that it cannot be indexed by a finite number of real parameters, other techniques of anaiysis, known as distribution free or nonparametric can be used. They are meant to be insensitive to the actual distribution.

One nonparametric techrique which has been applied to the analysis of nuclear accountability data is the wilcoxon test ${ }^{(12)}$. It consists first of ordering the data (inventory differences) by increasing absolute values, so that each ID is assigned an index $j$ according to its position in the ordered sequence. A rank sum is then formed, assigning a weight zero to the negative In's, and a weight $j$ to the posictve ID's.

If the rank sum is too large (above a certain chreshold) for a given number of ID's, one may have reason to suspect that diversion took place. The theory of the Wilcoxon test relates the rank sum threshold to the detection and false alarm probabilities. 


\section{V-Mask}

The V-Mask ${ }^{(13)}$ is a graphical tool used to examine CUSIM data and to decide when an alarm condition exists. Figure?.2 shows an example of application of the V-Mask to a sequence of fictitious data. A V-shaped mask is superimposed on a sequence of data points. The mask is translated on the plot and positioned in a constant relationship to the point being examined. If the points before the one being examined fall within the arms of the $V$, the situation is normal. If, on the contrary, one or more of the previous points falls outside the arms of the $V$, an alarm condition exists.

The sensitivity of the mask depends on the aperture of the $V$ and on the distance between the vertex and the point being examined. These two parameters can be related to the detection and false alarm probabilities.

\section{Alarm-Sequence Chart}

The alarm-sequence chart ${ }^{(14)}$ is a kind of pattern-recognition device which has been introduced in order to summarize the results of various statistical tests and to identify trends.

When a sequence of ID's causes an alarm, according to specified thresholds, it is represented by a pair of integers, which are the indexes of the initial and final ID in the sequence. The sequence is also assigned a descriptor, in the form of a letter, Indicating the increasing significance of the alarm. For example, the letter A indicates a larger false alarm probability than the letter $D$. The alarm-sequence chart is formed by plotting the descriptor at a position identified by the two integers, for each sequence causing an alarm. An example of alarm-sequence chart (from ref. 14) is illustrated in Figure 3.3.

\subsection{NRC Regulations and Guides - Criteria for Nuclear Materials Accounting}

This section represents a summary of the current NRC requirements and, as such, it does not necessarily enumerate all the 


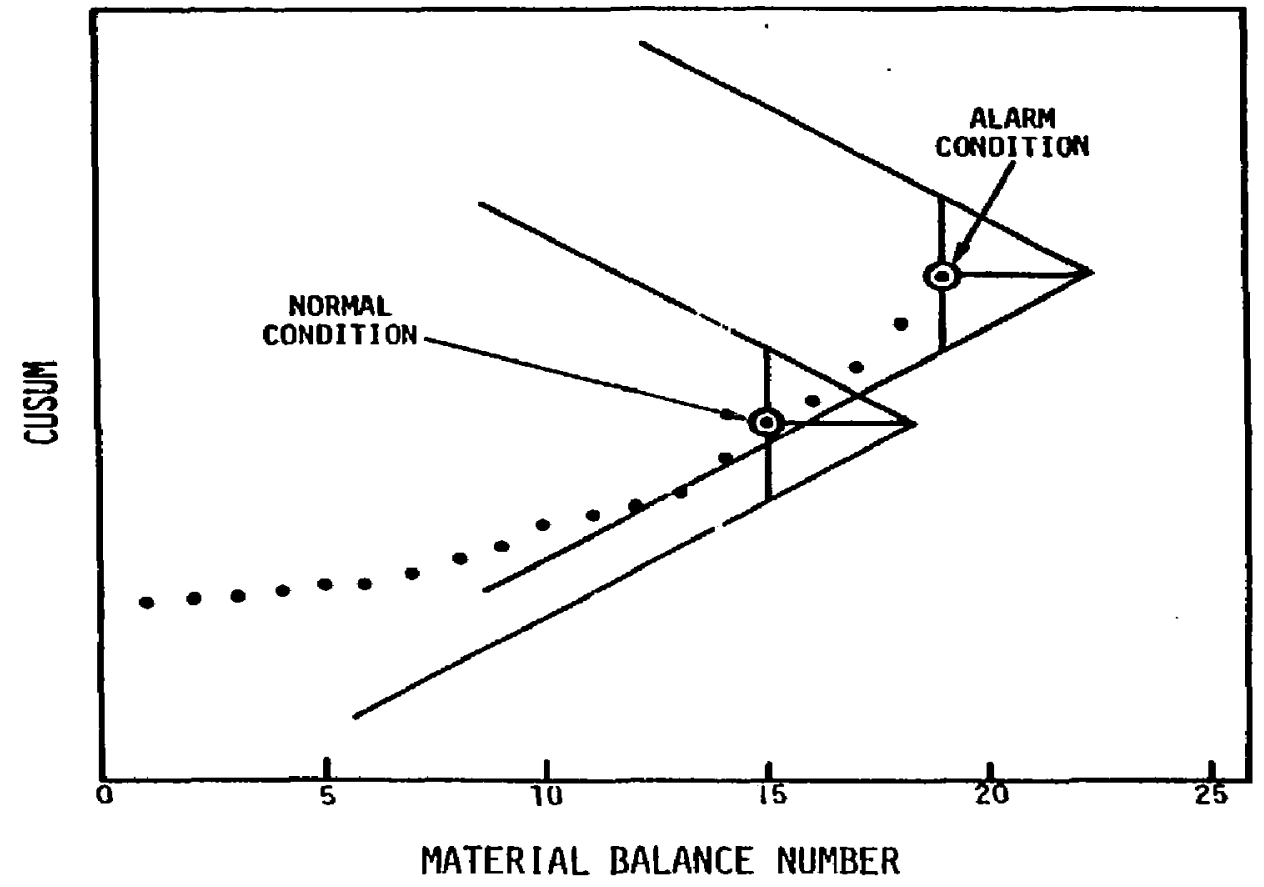

Figure 3.2 Example of Application of V-Mask to cusum Data 


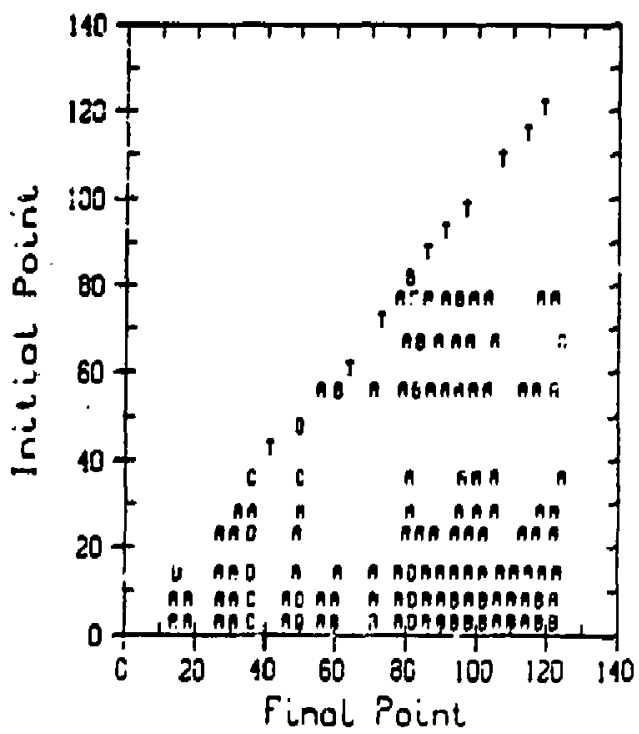

Eigure 3.3 Example of Application of the Alarw-Sequence Chart (Eron Ref. 14) 
requirements for nuclear material control and accounting is presented in Reference 16. A recent statement of the fundamental nuclear material controls promulgated by NRC in 10CFR Part 70 and the associated Regulatory Division 5 Guides is sumarized in Table 3.2.

Material control and accounting requirements applicable to licensees authorized to possess more than one effective kilogram of special nuclear material in unsealed form are discussed below. Following that each of the sub-systems that make up accounting are discussed.

\section{Tacility Organization}

Responsibility for the material control and accounting functions must be assigned to a single individual at an organizational level sufficient to provide independence of action. The special nuclear material custodial, measurement, accounting, and audit functions must be separated in a manner which assures that the activities of one organizational unit or individual serves as controls over and checks the activities of another organizational unit or individual.

\section{Facility Operation}

Material Balance Areas (MBAs) or Item Control Areas (ICAs) must be established for physical and administrative control of nuclear material. The custody of all nuclear material within any MBA or ICA must be the responsibility of a single individual. Each UBA must be an identifiable physical area such that material assigned to a given area is kept separate from naterial assigned to any other area, and such that the quantity of nucleat material moved into or out of an MBA is represented by a measured value.

Item Control Areas (ICAs) may be established according to the same critaria as that usad for Material Balance Areas (MBAs) except material is inventoried, and moved into and out of ICAs by item identity and count. The validity of previously measured quantities of SMM must be assured by the application of tamper indicating seals or devicas applied to each item or container. The number of ICAs and MBAs established at a plant must be sufficient to localize nuclear macerial losses or thefts. 
1. The responsibility for the development, revision, implementation and enforcement of safeguards procedures and the management of the overall facility safeguards should be assigned in writing.

2. The management system should provide for review of the nuclear materials control and accounting system by individuals independent of the material control and accounting organization on at least an annual basis.

3. Material Balance Areas (MBA) and Item Control Areas (ICA) should be established in a manner and in sufficient numbers to identify and localize losses.

4. The custody of plutonium within any MBA or ICA should be the respunsibility of a single designated individual.

5. A system should be established for the measurement of the pluconium content of all receipts, shipments, discards, and material on inventory.

6. A program of standardization and calibration of measurement equipment ana analytical procedures should be established and maintained.

7. Procedures should be established for shipping and receiving control of SSNM in order to ensure the accurate identification and measurement of receipts and shipments of SSNM, and taking of appropriate investigative and corrective action to reconcile shipper-receiver differences and the maintenance of approp:iate records.

8. A focumented system of control over the storage and internal transfer of SSMM within the facility should be maintained.

9. Procedures for the control of SSM scrap control should be established including identification and classification and regular processing and recovery.

10. Physical inventory procedures should be established, followed and maintained.

11. A system of records and reports to provide sufficient information to locate SSMM and to close material balances around each $M B A$ and the total plant should be established. 


\section{Measurement and Statistical Controls}

The licensee is required to determine by measurement the nuclear material content of all receipts, shipments, discards, and material on inventory. The identity of the various measurements that are used in nuclear material control, including a description of measurement methods and procedures with statements of measurement uncertainties must be provided. Error models including the basic statistical methodology and techniques are required to demonstrate the licensees' capabilicy to meet adequate measurement criteria.

Plant operators are required to establish and maintain a measurement control program covering all of the components of measurements used for material contrel and acsounting purposes. This program must include organizational controls for the manegement of measurement quality, training and performance gualification require-ments, a standards and calibration system, a quality testing system for the determination and the control of systematic and randow. errors, a records evaluation system for the collection and statistical analysis of data, and a system of management audits and reviews.

\section{Inventories}

NRC requires physical inventories of plutonium, uranium-233. and uranium enriched $20 \%$ or more in the isotope uranium-235 to be conducted every two months except for material that is in the inaccessible portion of an irradiated-fuel reprocessing plant. Uzanium enriched less than $20 \%$ in the isotope uranium-235, plutonium-238 and all special nuclear material in the inaccessible portion of irradiated-fuel reprocessing plants must be inventoried Every 6 monchs.

Ecr each accounting period terginated ty a physicai invercur: the inventory discrepancy (ID) value must be calculated. when an excessive ID occurs, the plant operator is required to lncate the ID if possible, to find its cause, and to take corrective acricns to prevent recurrence. 


\section{Shipping and Receiving}

As a rule, shipments and receipts are required to be independencly measured by both the shipper and recelver.

Shipper/receiver differences must be reviewed and evaluated on an individual container or lot basis, on a shipment basis, and on a cumulative basis for shipments of like type material. Appropriate investigative action must be taken on all shipper-receiver differences greater than 50 grams which are stetistically significant at the $95 \%$ confidence level to decide whether corrective action is necessary, or more important, whether diversion or theft has occurred.

\section{Management of Material Control System}

Audits are required of the material control and accounting programs annually by licensee management not connected with the safeguards program. The results of these reviews and audits must be documented, reported to appropriate plant management, and be kept available at the facility for inspection for a period of five years. Investigation of losses of discrete items or containers must be conducted and the results of the investigation reported to $1 \mathrm{i}$ censee management and to the WRC.

\subsection{LEID and Diversion of Nuclear Material}

This section will illustrate the application of LEID results to safeguards activities against the diversion of nuclear materials. A diversion might involve an atcempt to remove all the material desired in a single period between materlal balance inventories or in a series of small diversions over many accounting periods. An analytical model was developed to estimate the likelihood that either of such actions would be detected by material balance inventories. (18)

It was assumed that discrepancy limits were set at twice the standard deviation $(6)$ of the material balance discrepancy calculated on the basis of process measurement uncertaincies. This is In keeping with the LEID defined in 10 CFR 70 . With such a threshold, false alarms would normally oczur in 1 out of 44 inventories. 
Using this model, Figure 3.4 indicates how precise the material balance must be to achieve a specified confidence of detection of an attempt to accumulate two kilograms of plutonium. The three cases shown assume that two kflograms are accumulated by diversion in one, five, or an unlimited number of accounting intervals. The cuive related to diversion over an unlimited number of intervals assumes that the person attempting the diversion is aware of the accounting accuracy and removes the fractional amount during each accounting period that maximizes his overall probability of accumulating two kilograms without causing the inventory balance discrepancy to ever exceed the alarm threshold. As such, this curve depicts an upper bound on the probability that a diversion will remain undetected.

The figure shows that, for accounting to provide a high confidence (defined as 90 percent) of detecting that a diversion has occurred, a 20 accounting period process measurement uncertainty of no more than $0.28 \mathrm{kilogram}$ of plutonium is required to protect against diversiun of small amounts over numerous accounting periods to obtain two kilograms, and an uncertainty of no more then 1.2 kilograms of plutonium is required to detect the removal of two kilograms in one accounting period.

Table 3.3 sumarizes material balance uncertainties for a model fuel fabrication facility which is discussed in reference $1 \overline{8}$. The results of these computations show chat, for most MBA's in a fuel fabrication plant, a weekly (or less) material balance could reliably detect a diversion of two $\mathrm{kg}$ of plutonium during that period. If the two $\mathrm{kg}$ were accumulated over several inventory periods, the diversion would be reliably detected by material balances in only a few MBA's. 


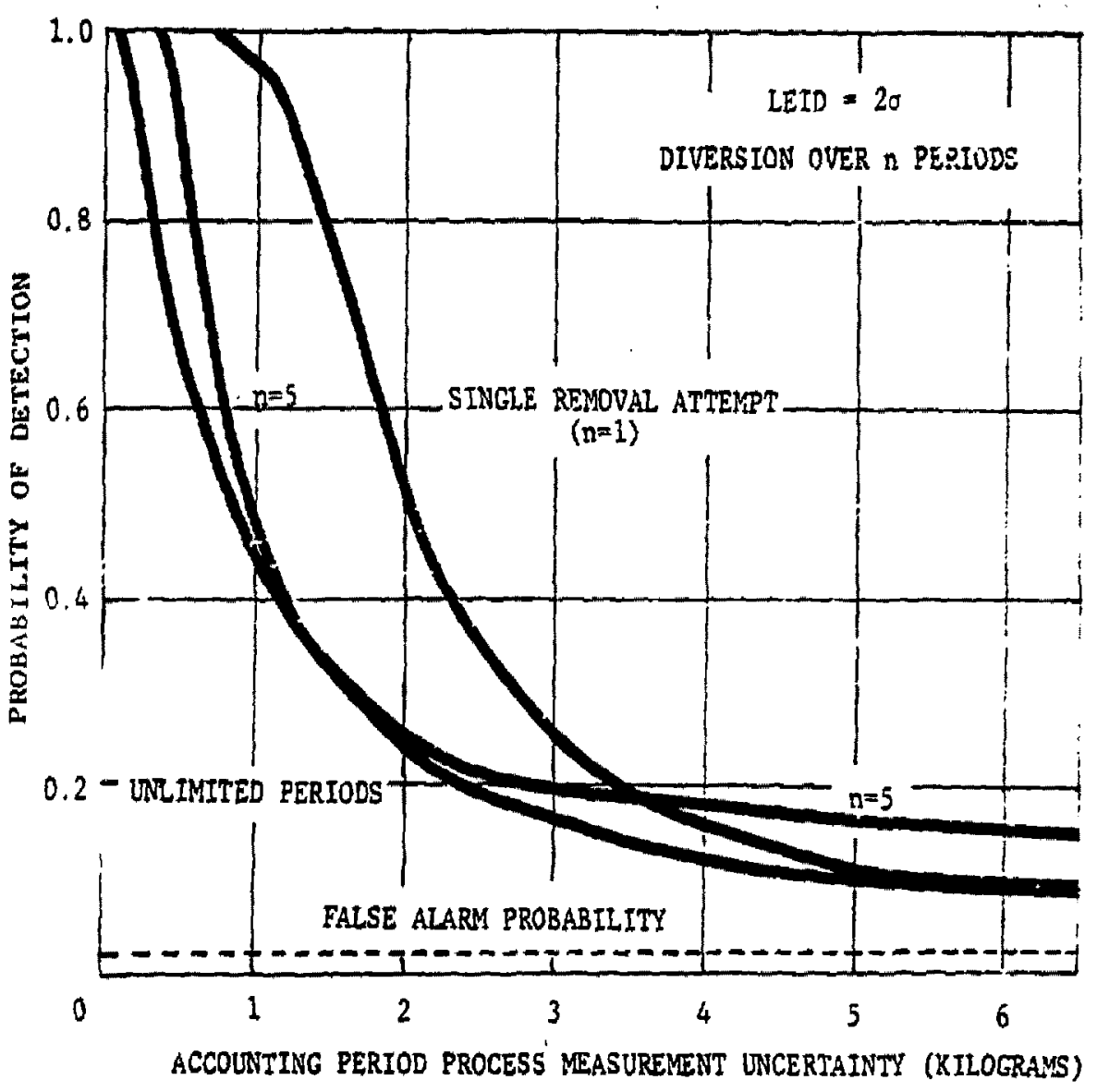

Figure 3.4 Accounting Period Accuracy Required to Detect Diversion of 2 Kllograms of Plutonium 
TABLE 3.3

PREDICTED LEID FOR

LUR FURL FABRICATION PLANT (20)

Inventory Interval

$\mathrm{MN}_{2}$ inloading,

Elending, and storage

1.36

1.60

2.38

$\mathrm{MO}_{2}$ Blending and

$\begin{array}{lll}2.09 & 3.74 & 2.31 \\ 0.64 & 0.79 & 2.05\end{array}$

Feilezizing

End of

Weekly

Monthly

8-Hour Shift

After Runout

After Clear.out

(kg)

(kg)

(kg)

Green Pellet Storage and Fellet

Sirtering

0.10

0.55

2.02

Sinterec' Fellet

Storage and

Pellet Grinding

0.43

0.77

1.95

Pellet Inspection and Storage, and Fuel Rud Loading

$\begin{array}{lll}0.45 & 0.67 & 1.89\end{array}$

Fuel Rod Repair and Jismantling

0.21

0.37

0.13

Clean Scrap Kecovery System

0.52

0.49

0.44

Anaiyticai jervices Facility

0.283

0.283

0.283 


\section{REFERENCES FOR SECTION 3}

1. J. L. Jaech, "Statistical Methods in Nuclear Material Control," USAEC TID-26298, 1973.

2. G. R. Bray, T. Gozani, L. Harris, Jr., H. Kendrick, L A. Kull, J. R. Ludwig, J. A. Maly, M. F. Mazur, W. P. Malling, and D. E. Rundquist, "Material Control and Accounting for Plutonium Recycle Facilities," SAI-76-539-LJ, March 1976.

3. T. I. McSweeney, J. W. Johnston, R. A. Schneider, and D. P. Granquist, "Improved Material Accounting for Pluconium Processing Facilities and a 235-U-HTGR Fuel Fabrication Facility," Battelle-Pacific Northwest Laboratories Report SNWL2098, October 1975.

4. E. A, Hakkila, J. W. Barnes, T. R. Canada, D. D. Cobb. S.T. Hsue, D. G. Langner, J. L. Parker, J. P. Shipley, and D. B. Smith. "Coordinated Safeguards for Materials Management in a Fuel Reprocessing Plant," Vol. II, LA-6881, Sep Cember 1977.

5. K. B. Stewart, "Minimum Variance Linear Untiased Escimates of Loss and Inventory," Nuclear Materials Management, $\underline{6}$. No. $4,47,1977$.

6. A. J. Duncan, "Quality Contrel and Industrial Statistics," ?. D. Irwin, Inc., 1965.

7. W. D. Evans, "When and How to Use Cu-Sum Chares," Technometrics, , No. 1, 1, February 1963.

B. H. W. Sorenson, "Least Squares Estimation: From Gauss to Kalman," IEEE Spectrum, July 1970.

9. A, Gelb, "Applied Optimal Estimation," MIT Press, Cambridge, MA, 1974.

10. D. H. Pike and G. W. Morrison, "A New Approach to Safegeards Accounting," ORNL/NUREG/CSD-1, 1977.

11. J. L. Jaech, "On Forming Linear Combinations of Accounting Data to Detect Constant Small Losses," Nuclear Materials Management, 6 , No. 4, 37, 1977. 
12. J. B. Thomas, "Nonparametric Detection," Proc. IEEE, Special Issue on Detection Theory and Applications, 58, 623, 1970.

13. J. M. Lucas, "A Modified V-Mask Control System," TechnomeElics, 15, 833, 1973.

14. H. A. Dayem, D. D. Cobb, R. J. Dietz, E. A. Hakkila, E. A. Kern, J. P. Shipley, D. B. Smith, and D. F. Bowersox, "Coordinated Safeguards for "atorials Management in a Nitrateto-Oxide Conversion Facili $y_{4} "$ LA-7011, April 1978.

15. Glancy, J.E., et.al., "The Ability of Periodic Accounting to Provide Nuclear Material Safeguards Assurance," SAI-76-781-IJ-R, Science Applications, Inc. 's study for Lawrence Berkeley Laboratory, (March 1977).

16. U.S. NRC A Study of Muclear Material Accounting, NUREG-0290, Vo1. 2, (June 1977).

17. Glancy, J.E., et.al. "Characterization of lluclear Material Accounting Systems," SAI-76-781. LJ, Science Applications, Inc.'s study for Lawrence Berkeley Laboratory, (December 15, 1976).

18. U.S. MRC Safeguarding a Domestic Mixed Oxide Industry $\triangle$ gainst a Hypothetica! Subrational Threat, NTREG-0414, (Nay IOTg?. 


\section{ACCOUNTABILITY APPLICATION TO A MODEL FACILITY}

In this chapter the accountability methods presented in Chapter 3 will be applied to present an example LEID calculation.

The model LWR mixed-oxide fuel fabrication facility that is presented in reference 1 will be used as the basis for the calculation. The process flow sheet is shown in Figure $4.1^{(1)}$. The facility has been broken into MBA's and ICA's following the method that has been used in previous safeguards analyses $(2,5)$. (See Figures 4.2 and 4.3).

\subsection{LEID Calculation}

In what follows, the equations for computing the LEID, as presented in Section 3, will be used to give an example of IEID for an MBA of the model fabrication facility receiving $\mathrm{MO}_{2}$ containing 30 weight percent $\mathrm{Pu}$. Assumptions used in computing the LEID will be discussed first followed by a discussion of the LEID and how the length of the accounting period affects the LEID.

The LEID calculation is based on material flows presented in Figure 4.1. The material balance area selected for the sample calculations is MBA No. 1 (see Figure 4.2). Figure 4.4 shows a blown up segment of Figure 4.1 that encompasses MBA No. 1. It includes average Pu flows per shift and indicates key measurement points. Measurement designations are defined in Table 4.1. Assumptions used in the calculation are:

- A weighing, sampling, and analysis is performed on each canister received from $\mathrm{MO}_{2}$ storage $\left(\mathrm{N}_{\mathrm{W}}=\mathrm{N}_{\mathrm{S}}=\mathrm{N}_{2}=1\right)$.

- For NDA measurement one measurement is performed per batch $\left(N_{w}=1\right)$.

- Transfers from the $\mathrm{MO}_{2}$ bulk storage vessel are weighed in $30 \mathrm{~kg}$ hoppers $\left(N_{w}=19\right)$. 


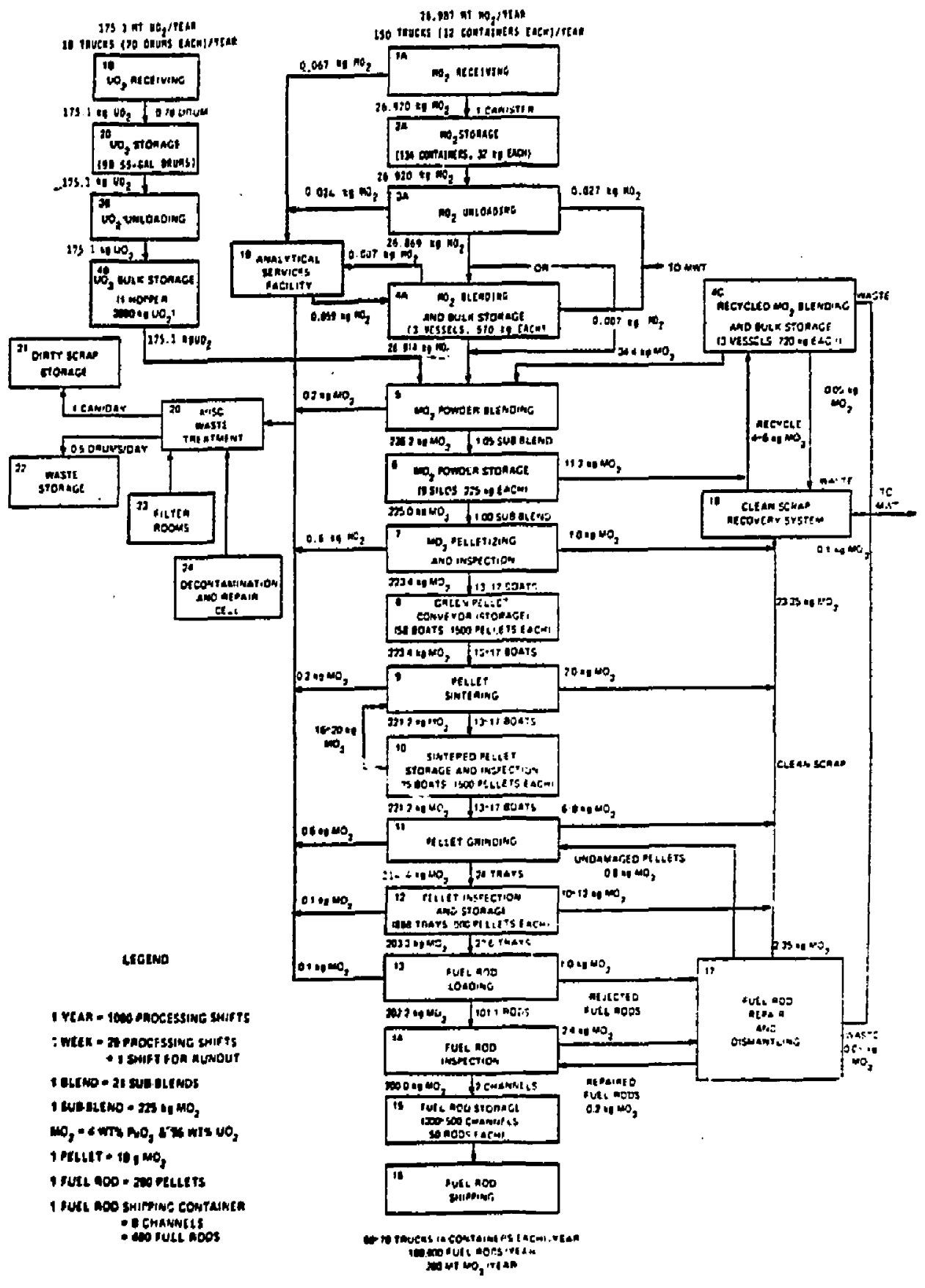

Figure $4.1 \mathrm{MO}_{2}$ Process Line (average flow per 8-h shift) 


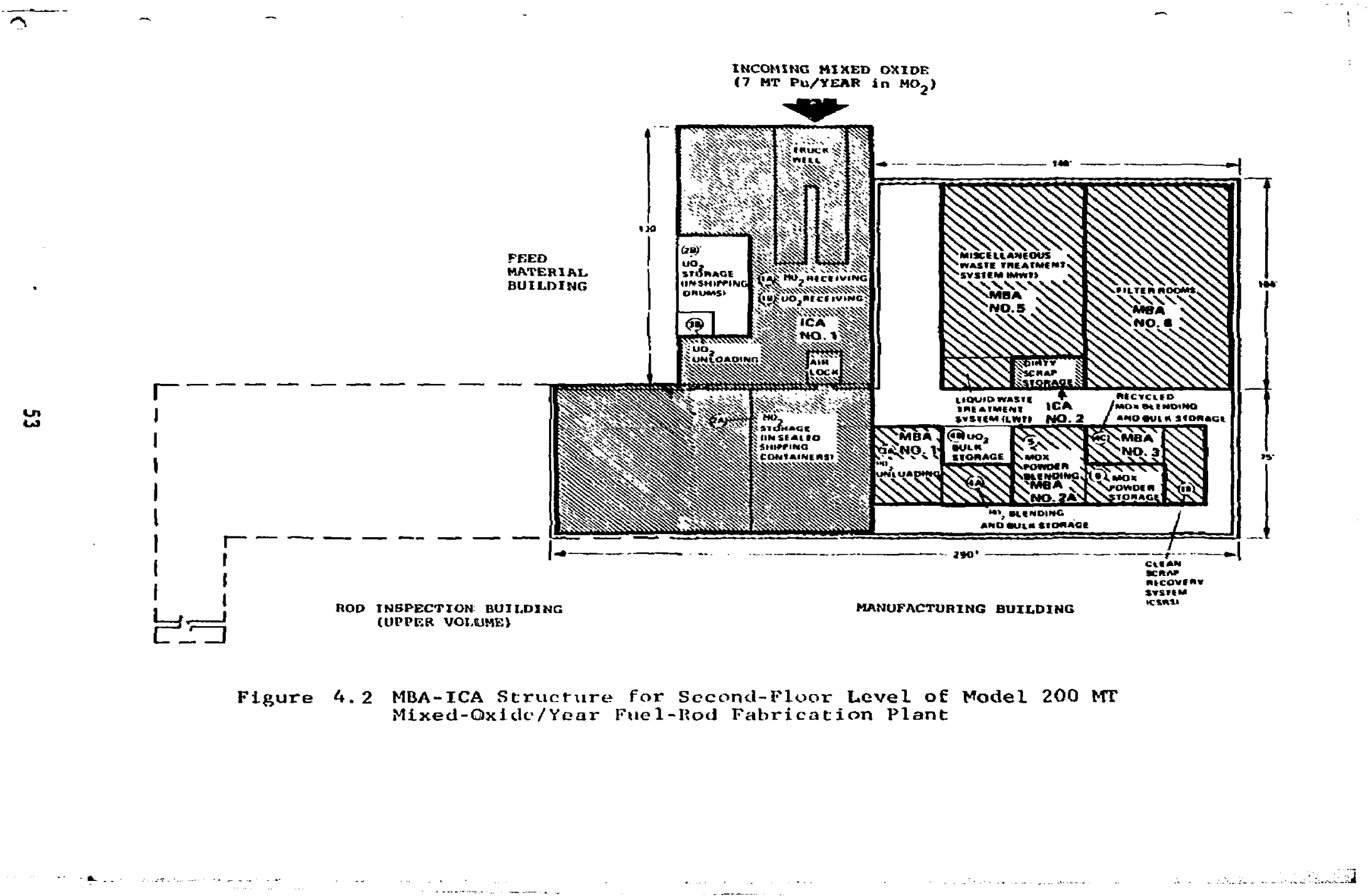




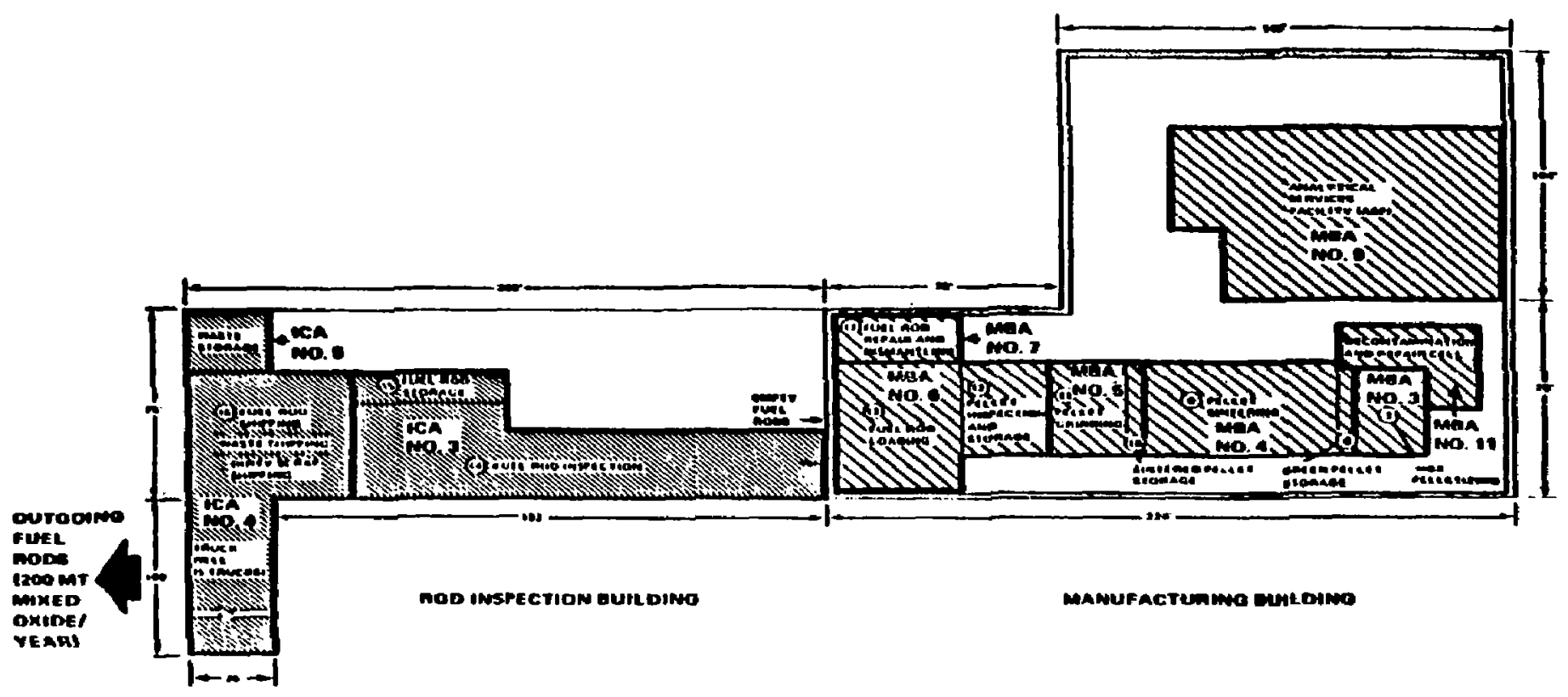

Figure 4. 3 MBA-ICA Structure Eor First-Floor Level of Model $200 \mathrm{MT}$ Mixed-Oxide/Year Fuel-Rod Fabrication Plant 


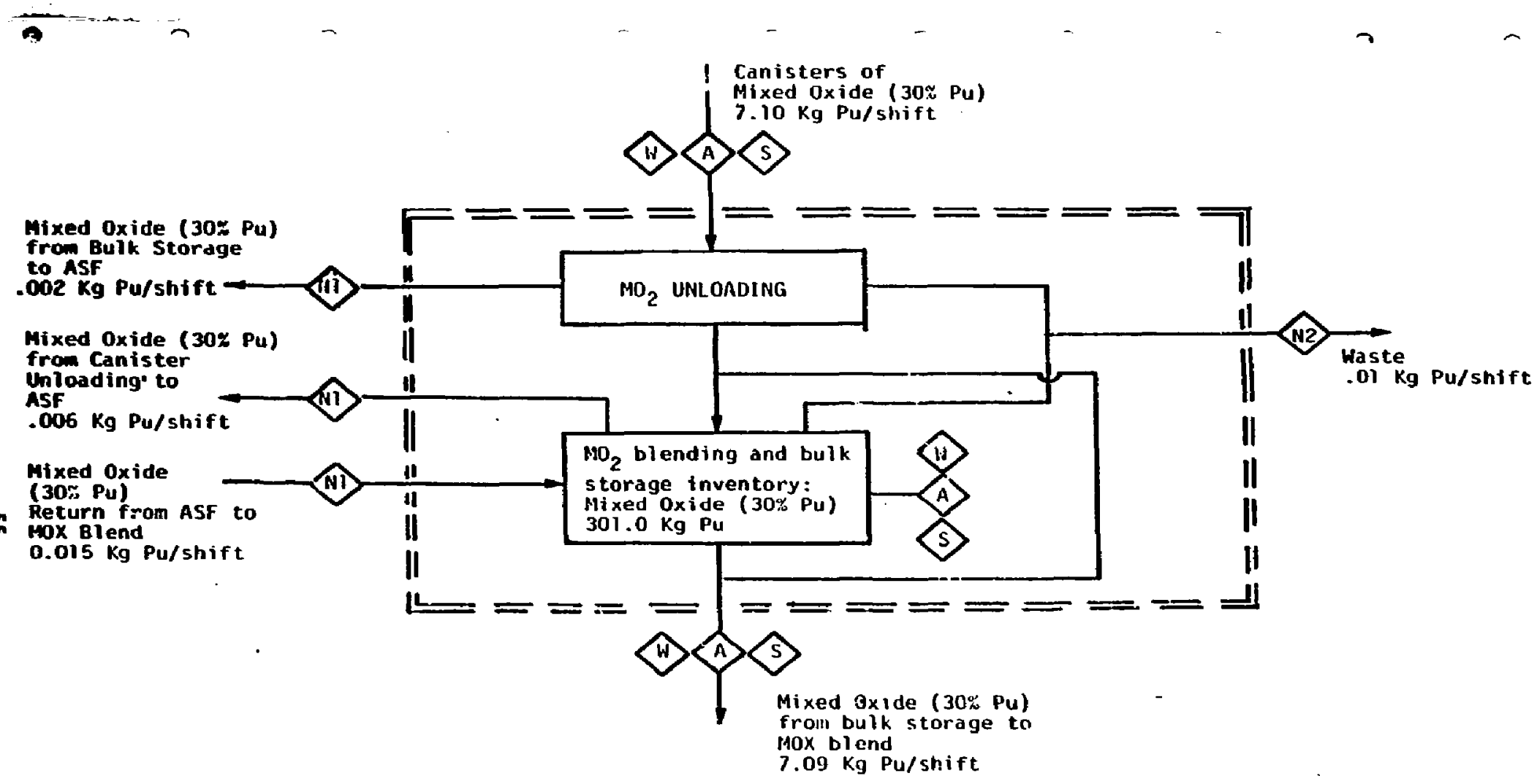

Figure 4.4 Flow per shift and typical inventory for MBA No. 1 in model MOX Fabrication Plant 


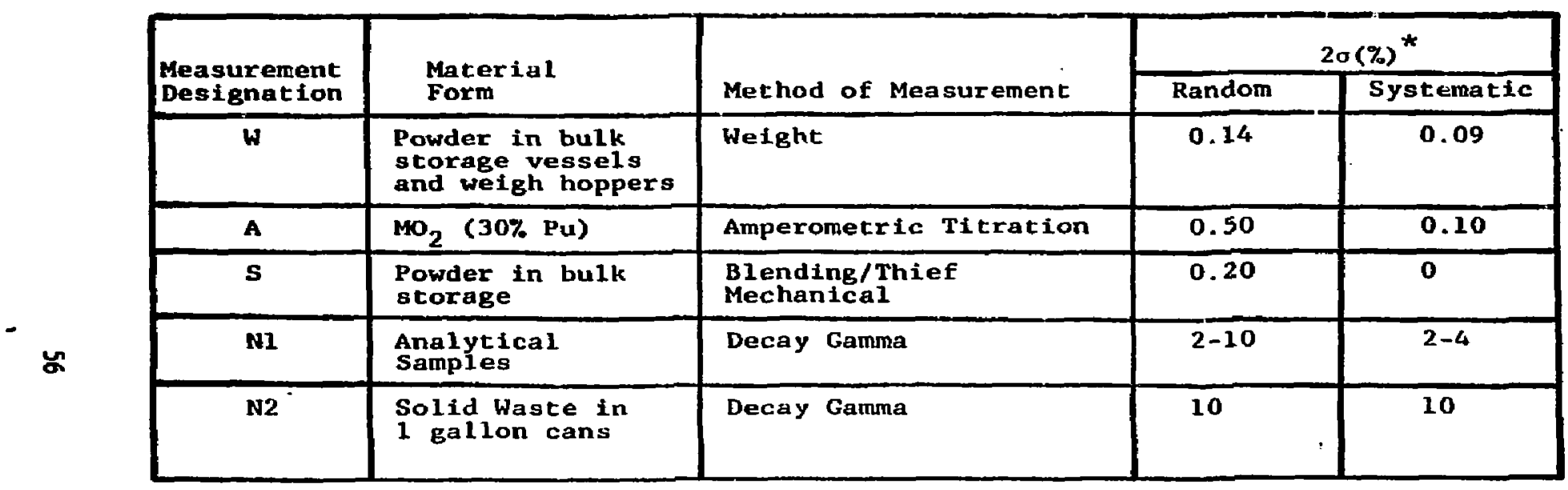

* Values taken from referemce 5

Table 4.1 Measurement Methuds and Uncertainties for MBA No. 1 
c Weight inventory of the $\mathrm{MO}_{2}$ bulk storage vessel is done by a load cell $\left(\mathrm{N}_{\mathrm{w}}=1\right)$.

- One sample and analysis is performed on the $\mathrm{MO}_{2}$ bulk storage vessel per batch $\left(\mathbb{N}_{s}=N_{a}=1\right)$.

- The calibration period is equal to the accounting period $(M=1)$.

- Plutonium content of the inventory does not change with time $\left(C_{b j}=C_{e j}, I_{b k}=I_{e k}\right)$.

- Fraction of difference (FD) and fraction of sum are both equal to $.5(F S=F D=.5)$.

- Syscemaric errors presented in Table 4.1 are assumed to contain both long-term and short-term uncertainties $\left(\sigma_{i}^{2}\right.$ (of Table 4.1) $=p_{i}^{2}+q_{i}^{2}$ ).

Table 4.2 contains material streams and inventories encountered in MBA No. 1. For each stream and inventory, the measurement technique used to determine the fissile content is indicated. Also, the batch on which the measurement is made, the typical size of the batch, and estimates of the percent random and systematic errors on the amount of fissile material in a batch are reported. Values of the random and systematic errors given in Table 4.2 nave been coupluted using the 20\% numbers presented in Table 4.1.

Table 4.3 contains the measurement errors for the various conponents of transfers and inventory in the MBA, assuming a two week inventory period. For each component, the random and systematic error (from Table 4.2) and the contribution to the LEID are also indicated. The total LEID is calculated by combining quadratically the various contributions. 
TABLE 4.2 MEASUREMENT UNCERTAINTIES ON TYPICAL AMOUNTS OF FISSILE MATERIAL, USED TO COMPUTE MATERIAL BALANCE UNCERTAINTIES

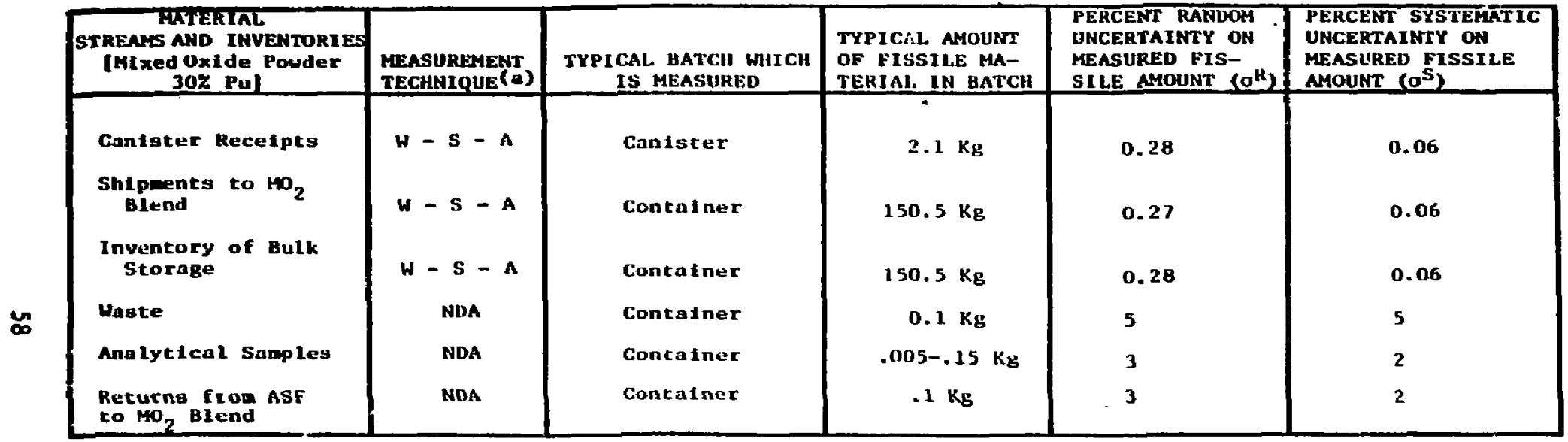

(a) W - Welght S - Sample A - Analyze

NDA - Non Destruct Ive Assay 
TABLE 4.3 EXAMPLE OF PLUTONTUM LEID CALCULATION FOR MODEL MBA (BIWEEKLY ACCOUINTING PERIOD)

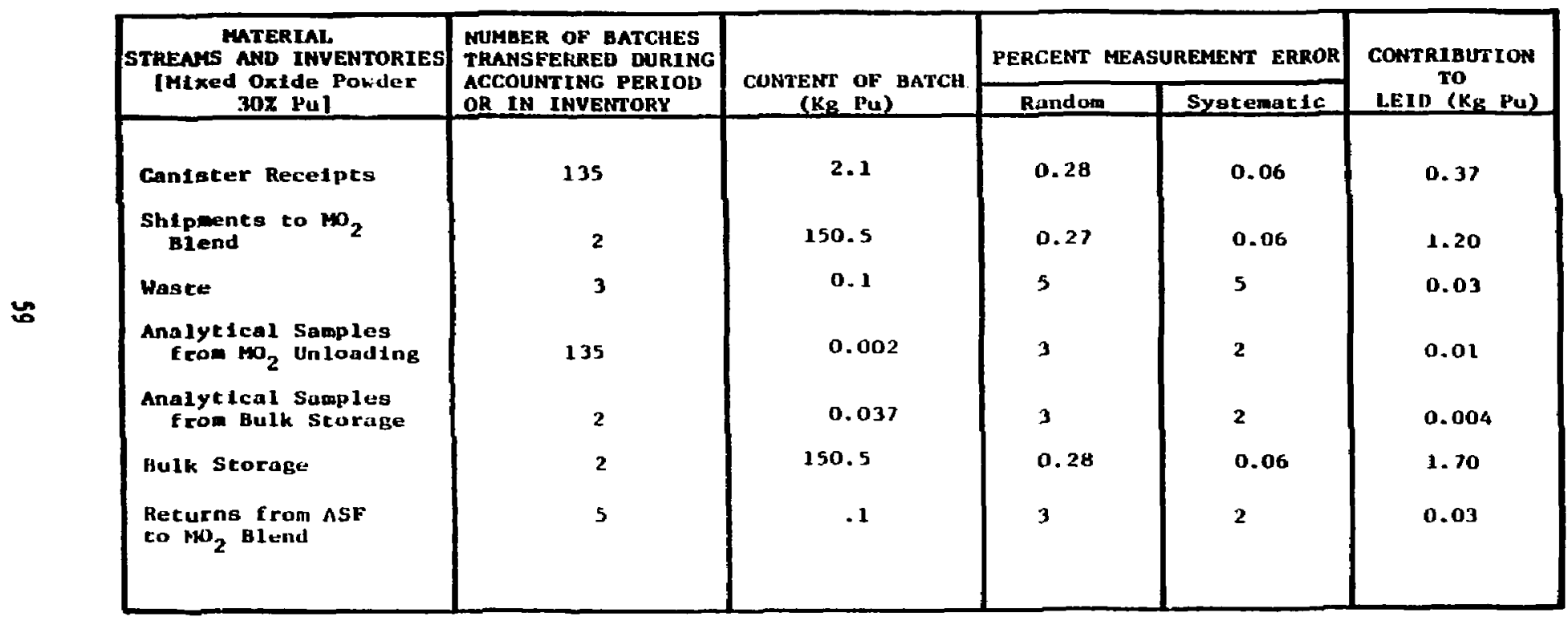

TOTAL LEID (20) : $2.12 \mathrm{~kg} \mathrm{~Pa}$ 
We are now in a position to discuss the effect of a change in the length of the accounting period on the LEID. Changing the accounting period will change the number of batches being transferred, while the number of batches in inventory presumably will not change. The form of the LEID equation indicates that there will be three contributions to the LEID, namely:

- A constant contribution due to the inventory uncertainty.

- A contribution which is proportional to the square root of the length of the accounting period. This is due to random errors on transfers.

- A contribution which increases linearly with the length of the accounting period. This is due to systematic errors on transfers.

Figure 4.5 shows the variation of the LEID with accounting period for the model MBA described previously and based on the uncertainties given in Table 4.3. It can be seen that the main contribution to the LEID comes from systematic errors on transfers. In principle, there are two ways of reducing the LEID. The first way is to reduce the systematic errors by frequent recalibration of the measuring instruments or by establishing a measurement control program. The second way is simply to shorten the length of the accounting period. With regard to this second strategy, the following should be noted:

- Shortening the accounting period permits one to reduce the threshold of detection for a single theft during an accounting period. However, it does not increase the probability of detection of a sequence of thefts, in which an amount lower than the LEID is diverted during each accounting period.

- Shortening the accounting period has a negative effect on plent productivity, since a certain ameunt of downtime is of necessity associated with the process of taking inventory. Therefore, unless real time accountability or dynamic inventory techniques are implementod, there are constraints which prevent reducing the accounting perlod below a limit which is practical from. an operational viewpoint. 


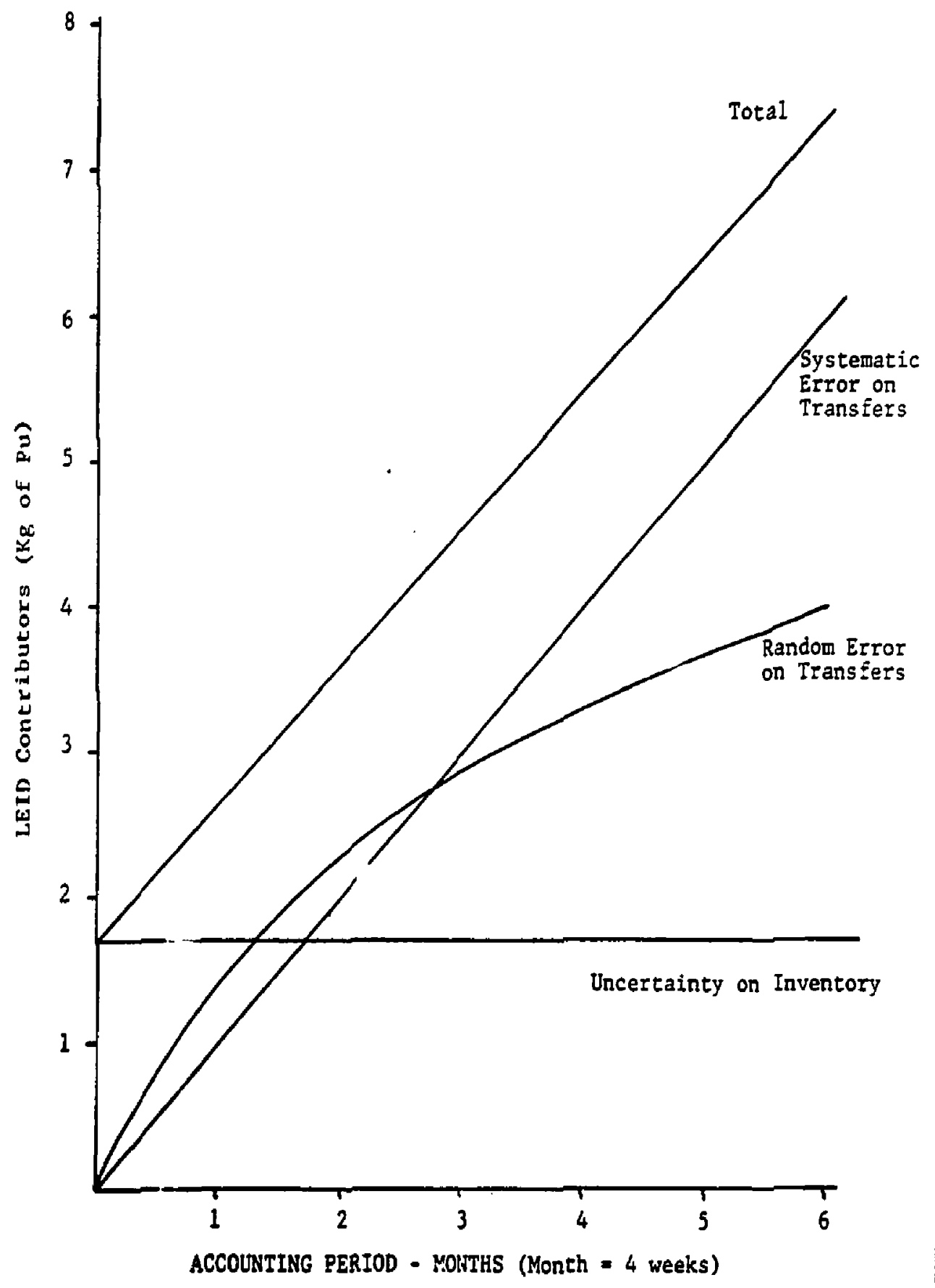

Figure 45 Total LEID and Contributions to LEID for MBA No. 1 of Model $\mathrm{MO}_{2}$ Fabrication Plant 


\section{REFERENCES FOR SECTION 4}

1. G. Borgonovi, et. al, "Addendum to Part I-Material Coutrol in Nuclear Fuel Fabrication Eacllities", SAI Refort No. SAI79-788-WA, submitted to LLL, October 1978.

2. Shipley, J.P., et. al. "Coordinated Safeguards for Materials Management in a Mixed-onide Fuel Facility," Los Alamos Scientific Laboratory, LA-6536, (February 1977).

3. Bain, E.E., Jr., et. al., "An Evaluation of Real-Time Material Control and Ancountability in a Hodel Mixed-oxide Fuel Plant," Science Appilications, Inc., report SAI-75-648-LJ, (September 1975).

4. Eray, G. R., er. al., "Material Control and Accounting for Plutonium Recycle Facilities," SAI-76-539-LJ, Science Applications, Inc. 's study for the Nuclear Regulatory Conmission, (March 1976).

5. McSweeney, T.I., et. al. "Improved Material Accounting for: Plutoniun Processing Facilities and a ${ }^{2}$ U-HTGR Fuel Fabrication Facility:" Battelle Pacific Northwest Labcratories, unnumbered report, (Óctober 1975).

Reference lo a company or product name dues not imply approval or recommendation of the producl by the University of California or the U.S. Department of Energy to the exclusion of others that may be suitable.

\section{NOTICE}

"This report was prepared as an account of work "This regort was prepared as an acouter of work sponsored by the United Staies Cuited States Department of Energy. nor anv of their employees. nor any of their contractors, subcon'ractors, or their cmplojees, maks any warranty, express o: implied, or assumes any legal liability or responsibility for the aceurocy, completeness or usefulness of any iniosmation. appa falus, product of ptocess dischosed. of represents that its use would not infringe privalcty-ownes rights. 